\title{
Taxation of Labor Income and the Demand for Risky Assets
}

\author{
Douglas W. Elmendorf \\ Federal Reserve Board \\ Miles S. Kimball \\ University of Michigan \\ Jùne, 1996
}

We analyze the effect of labor income risk on the joint saving/portfolio-composition problem. It is well known that when private insurance markets are incomplete, the insurance afforded by labor income taxes can reduce overall saving through the precautionary saving motive. This insurance may change the composition of saving as well, because the reduction in labor income risk may affect the amount of financial risk that an individual chooses to bear. We find that, given plausible restrictions on preferences, any change in taxes that reduces an individual's labor income risk and does not make her worse off will lead her to invest more in risky assets. This result holds even when labor income is statistically independent of the return to risky assets. We also find that the effect of labor income risk on financial risk-taking can be quantitatively important for realistic changes in tax rates.

We would like to thank Louis Eeckhoudt, Benjamin Friedman, Roger Gordon, Greg Mankiw, and Andrew Samwick for helpful comments, and the National Science Foundation for financial support. The views expressed here are our own and not necessarily those of the Federal Reserve Board or its staff. 
What is the effect on saving of a reduction in current taxes combined with an offsetting increase in taxes later in an individual's life? In a world of perfect capital markets and no uncertainty, the individual should save the entire amount of the tax cut. In the real world, however, people face significant uncertainty about their future income, and because proportional or progressive income taxes reduce the variance of income, those taxes provide insurance against this uncertainty. An increase in future taxes increases this insurance and, through the precautionary saving motive, reduces an individual's saving relative to the Ricardian benchmark just stated (see Chan, 1983, Barsky, Mankiw and Zeldes, 1986, and Kimball and Mankiw, 1989). The increased insurance provided by higher future taxes may have another effect on saving as well: it may change the composition of saving, because the reduction in labor income risk can affect the amount of financial risk that an individual chooses to bear. In this paper we explore the effect of labor income taxes on the willingness to bear financial risk.

We study a two-period life-cycle model in which individuals make two choices: how much to save in total, and how to divide that saving between a risky asset and a risk-free asset. We find that, given plausible restrictions on preferences, any change in taxes that reduces an individual's labor income risk and does not make her worse off will lead her to invest more in the risky asset. This result holds even when labor income is statistically independent of the return to the risky asset, although not if the risky asset actually provides insurance for labor income risk. We also find that the effect of labor income risk on financial risk-taking can be quantitatively important for realistic changes in tax rates.

Consider again the deferral of labor income taxes with no change in the expected value within a person's lifetime. In a neoclassical world with certain labor income, this tax reduction leaves national saving unchanged by raising private saving as much as public saving falls. It also has no effect on investment in the risky asset, because the future tax liability involves no risk and individuals want to offset that liability by holding more of the riskless asset. In a world with uncertain labor income, however, our analysis shows that deferring labor income taxes raises investment in the risky asset. ${ }^{1}$ In essence, individuals respond to a reduction in one risk by increasing their exposure

1 The Economic Report of the President (1996, p. 88) asserts our result without proof, as well as asserting the desirability of risk-taking and the importance of the adverse selection problem that we discuss below: "This income insurance [of progressive taxation] has the direct benefit of reducing the income risk borne by individuals themseives, shifting it to society as a whole, but it also provides an indirect benefit. Because households will be willing to bear more risk if they have access to income insurance, they will undertake investments (in both financial and human capital, including inčreased labor mobility) with greater risk and greater expected return. Aggregated over all individuals, the effect of undertaking such investments is a higher expected national income. Private markets will not offer such income insurance because the inherent difficulty of separating effort and luck from an individual's ability subjects private purveyors to adverse selection: those who expect poor outcomes would be more likely to purchase the insurance. The income tax system, in contrast, applies to virtually all 
to another risk. ${ }^{2}$ Surprisingly, the effect of this tax deferral on overall saving becomes unclear once we allow for changes in financial risk-taking. If the uncertainty of labor income were the only risk faced by an individual, then the standard analysis would apply: the individual would consume more and national saving would fall. But when the individual has the opportunity to invest more in the risky asset, the additional uncertainty that this action creates will tend to decrease consumption and raise saving. In fact, we cannot rule out the possibility that this indirect precautionary effect might outweigh the direct precautionary effect and produce a net increase in saving.

Our analytic results raise two questions. First, is the effect of taxes on labor income risk quantitatively important in people's portfolio selections? We argue that it is likely to be important and present some illustrative calculations to that effect in the penultimate section of the paper. Second, is encouraging greater financial risk-taking a socially desirable or undesirable feature of labor income taxes? In their seminal paper on taxes and risk-taking, Domar and Musgrave (1944) write that "there is no question that increased risk-taking ... is highly desirable" (p. 391). They do not justify this claim, however, nor do most of the researchers who have followed them in work on this topic. A complete investigation of this issue lies well beyond the scope of this paper, although we can suggest several reasons why private markets might generate too little risky investment. ${ }^{3}$

First and foremost is the lack of a complete market for human capital. Because human capital risk is undiversifiable for an individual but largely diversifiable for society as a whole, there is no presumption that individuals will undertake the socially optimal amount of risky investment in either human or physical capital. Indeed, we think there is some presumption that the optimal conditions can be approached more closely by diversifying idiosyncratic human capital risk through the tax system. ${ }^{4}$

Imperfections in the market for financial capital may inhibit risky investment as well. For example, entrepreneurs may be unable to diversify away the idiosyncratic risk of their projects

economically active people, mitigating concerns with adverse selection."

2 This result is closely related to the findings of Pratt and Zeckhauser (1987) and Kimball (1991) that, for a broad class of utility functions, when an agent is forced to accept one risk, the agent will be less willing to accept other independent risks. Kimball's analysis is the more closely related to the analysis in this paper because (a) Kimball links the interaction between risks to the effect of the risks on expected marginal utility, which also governs consumption decisions, and (b) Kimball deals with differential changes in risk as well as with the discrete introductions of risk treated by Pratt and Zeckhauser.

3 We follow the literature in assuming that if individuals demand more risky assets, more risky projects will be undertaken. For example, Feldstein (1983) asserts that "the net rates of return on capital in different uses are not generally equal but reflect the risk-return preferences of investors and their equilibrium portfolio compositions" (p. 17).

4 To evaluate this presumption, one would need to explain why there is no private insurance against human capital risk. If the primary obstacle to private insurance is moral hazard, there is little reason to believe that the government can improve on the private market outcome. If adverse selection is an important obstacle, however, using the government's coercive power of taxation may make possible a social gain. See footnote 1. 
because adverse selection discourages the participation of outside investors. Since entrepreneurs' labor income is highly correlated with the return to their financial capital, increasing the labor income tax rate is especially likely to increase their risky capital investment, as we show later.

Third, the social return to risky investment will exceed the private return if there are technological spillovers or other positive externalities from such investment. For example, Shleifer and Vishny (1987) argue that aggregate demand externalities in an imperfectly competitive economy make the optimal amount of risky investment greater than the amount chosen (in the absence of taxes) by profit-maximizing firms. Fourth, capital income taxes at both the corporate and personal levels may have powerful effects on financial risk-taking. Unfortunately, there is little theoretical or empirical consensus on the direction or size of these effects, as shown by Sandmo's (1985) survey.

The paper is organized as follows. Section I discusses our work's relationship to previous research. Section II presents the model, and Section III gives the main results. Section IV considers the quantitative significance of the results, and Section $\mathrm{V}$ concludes.

\section{Relationship to the Literature}

In its analysis of the effect of labor income taxes on the demand for risky assets, this paper bridges two lines of research. The first is concerned with the role of income taxes in providing insurance for risky labor income, and the resulting effect on the consumption/saving decision. The starting point for this research is the analysis of the consumption/saving decision under uncertainty, which began in earnest with Leland (1968), Sandmo (1970), Rothschild and Stiglitz (1971), and Drèze and Modigliani (1972). Recent contributions include Skinner (1988), Zeldes (1989), Kimball (1990a,b), Caballero (1990), Weil (1991), and Kimball and Weil (1991). Some research in this group examines the aggregate demand effects of tax cuts-for example, the papers mentioned in the introduction. Other research evaluates the welfare effects of redistributive taxation-for example, Eaton and Rosen (1980), Varian (1980), Easley, Kiefer and Possen (1993), and Devereux and Smith (1994).

All of this work, however, focuses on the effect of labor income taxes on total saving and investment, and says little about the possible effects of these taxes on portfolio composition. For example, Drèze and Modigliani discuss portfolio choices but determine only the conditions for their separability from saving decisions and conclude that perfect insurance markets for labor income are essential for separation to hold. Varian determines the optimal tax schedule as a balancing of the direct beneficial effect of social insurance on people's utility and the detrimental effect of social insurance on people's saving. If it is appropriate to encourage investment in risky assets, then the 
implicit insurance provided by taxes has an additional benefit neglected by Varian.

The second line of research is concerned with the role of capital taxes in providing insurance for financial risks and thus affecting the amount of financial risk-taking in the economy. Domar and Musgrave (1944), and many following them, analyze optimal portfolio selection among a collection of fully marketable securities. Some of this research (summarized by Sandmo, 1985) includes the consumption/saving decision (Sandmo, 1969 and Ahsan, 1976) but does not allow for risky labor income. Friend and Blume (1975) discuss the role of human capital in their empirical study of the "market price of risk," but they assume a fixed amount of savings and do not address the role of taxes as insurance. Feldstein (1969) notes that "the optimal portfolio behavior for an individual is not independent of the uncertainty of his other income sources" (p. 762) but does not pursue the idea. Davies and Whalley (1991) analyze the effects of taxes on human and physical capital formation, but do not allow for uncertainty.

The existing analyses of financial capital do not suffice as analyses of human capital because of fundamental differences between the two assets. First, human capital can be acquired but not resold-that is, human capital investment is irreversible except for a small amount of depreciation. Thus, the timing of decisions to invest in human capital is different from that for investing in most financial assets. Second, the return to human capital depends on both unobservable effort and a large random element. This means that human capital risk is privately undiversifiable and uninsurable. Third, the random element in human capital returns is largely idiosyncratic. This provides the opportunity for the government to reduce each individual's human capital risk without taking on additional risk itself. ${ }^{5}$

This paper is also related to research on the possible "crowding in" of investment by government debt. Consider a reduction in taxes today accompanied by an offsetting increase in taxes in the future. Friedman (1978) argues that such a shift in the timing of taxes might reduce the cost of equity capital (though it would raise the cost of debt capital) and thus increase real investment. ${ }^{6}$ Auerbach and Kotlikoff (1987) discuss crowding in that results from deferring capital income taxes. Temporarily lower taxes encourage individuals to save more, and if this effect exceeds the reduction in saving caused by the transfer of some of the tax burden to future generations, crowding in will occur. Our results show that crowding in of risky investment is in fact likely to occur, but for a

5 Merton (1983) shows that "a tax and transfer system not unlike the current social security system can reduce or eliminate the economic inefficiencies" that result from the nonmarketability of human capital. Merton is concerned with the effect of aggregate labor income risk on financial risk-taking, not idiosyncratic labor income risk as in this paper.

6 His discussion of financial crowding out and crowding in abstracts from the real crowding out which would occur in a fully-employed economy. 
different reason than those previously discussed. We return to this point in the Conclusion.

\section{The Joint Saving/Portfolio-Composition Problem in the Face of Labor Income Risk}

Setting. Our analysis uses a simple two-period life-cycle model with additively separable utility:

$$
U\left(c, c^{\prime}\right)=u(c)+\mathbf{E} v\left(c^{\prime}\right)
$$

where $c$ is first-period consumption and $c^{\prime}$ is second-period consumption. Both absolute risk aversion and the absolute strength of the precautionary saving motive decrease with wealth. (We discuss these assumptions in more detail below.)

We assume that individuals earn a fixed amount of first-period labor income. That income combined with any initial wealth provides a fixed amount of wealth $w$ to divide between firstperiod consumption and saving. That saving can be invested in two assets-a risk-free bond with a real after-tax gross return of $R$, and a risky equity with a real after-tax excess return of $\tilde{z}$ (i.e., borrowing $\$ 1$ at the interest rate $R$ to buy $\$ 1$ of the risky security will yield on net, after taxes and repayment of the loan, the random amount $\$ \tilde{z}$ at the beginning of the second period)..$^{\overline{ }} \mathrm{We}$ assume that individuals can freely borrow or lend through the riskless asset and can freely invest in (or short) the risky asset.

Let $\alpha$ be the dollar value of the individual's investment in the risky asset at the end of the first period (not to be confused with the share of the portfolio in the risky asset). Then at the beginning of the second period, the value of all the individual's investments will be $R(w-c)+\alpha \tilde{z}$.

We assume further that individuals hold risky human capital from which they earn income in the second period. The amount of human capital will be considered fixed as an approximation to the difference in timing between decisions about human capital investment (primarily the choice of occupation) and decisions about financial investment. ${ }^{8}$ Labor is supplied inelastically. ${ }^{9}$

Following Barsky, Mankiw and Zeldes (1986), Kimball and Mankiw (1987), and Varian (1980), private insurance markets are assumed to be incomplete, leaving some amount of uninsured labor income risk. Some of this risk may be due to the possibility of disability, but probably a more

7 We are implicitly assuming that capital income taxes are linear.

8 See Kanbur (1981) and Driffill and Rosen (1983) on the choice of how much human capital to hold, and Faton and Rosen (1980) on the choice of the riskiness of human capital.

9 Bodie, Merton and Samuelson (1992) study the effect of future labor supply flexibility (as opposed to labor income uncertainty) on the portfolio decisions of the young. 
important source of uninsurable income risk is the possibility of doing worse than expected in one's career. This risk is difficult to insure for both moral hazard reasons (one might be tempted to expend less effort in advancing one's career if failure is cushioned by insurance) and adverse selection reasons (those who have private information that they will do poorly in the future will be more likely to buy insurance than those who know they will do well). Providing insurance also entails marketing and administrative costs. For our purposes, the reasons for the absence of such insurance are not important. As long we consider changes in tax parameters that are small enough that the amount of relevant private insurance remains at zero, we do not need to model explicitly why such insurance is unavailable. ${ }^{10}$

Thus, we model an individual's second-period labor income as a random variable $\tilde{y}$ with a fixed distribution. We want the joint distribution of labor income $\tilde{y}$ and the excess return $\tilde{z}$ to reflect both idiosyncratic income risk and the empirically observed positive correlation between aggregate labor income and the return on financial assets. ${ }^{11}$ So we assume that $\tilde{y}$ is the sum of three components: a constant $\bar{y}$, a mean-zero random variable $\epsilon$ independent of $\tilde{z}$, plus a fraction $\beta$ of $\tilde{z}$ itself. Formally:

$$
\tilde{y}=\bar{y}+\tilde{\epsilon}+\beta \tilde{z}
$$

(Note that $\bar{y}$ is not the mean of $\tilde{y}$, but the mean of the portion of $y$ that is uncorreiated with $z$.) As will be seen, our key conclusions hold even when $\beta=0$.

The government redistributes labor income through a proportional tax on income above a certain level $\left(y_{0}\right)$ and a proportional rebate on income below that level. Thus, after-tax income in the second period is $y_{0}+(1-\tau)\left(\tilde{y}-y_{0}\right) .{ }^{12}$ Note that any first-period labor income tax is effectively a lump-sum tax, because it interacts with neither uncertainty nor labor supply elasticity. And because there is Ricardian neutrality for changes in the timing of lump-sum taxes, any tax on first-period labor income can be treated as if it were a lump-sum component of second-period labor income taxes.

10 This strategy is shared by the papers cited at the beginning of the paragraph. Kaplow (1991) argues forcefully that this approach is not adequate when the purpose of the study, as in Varian, is to judge the merits of government insurance. But our goal is not to determine whether taxes are an efficient solution to private insurance market failure; we simply note the absence of private insurance and the existence of government insurance, and study the effects of this situation on other features of the economic landscape.

11 See Barsky, Mankiw and Zeldes (1986).

12 Labor income taxes need not be linear as long as the contemplated change in labor income taxes is linear, since one could let $\tilde{y}$ represent after-tax labor income under the original tax policy and then let $\tau$ represent a linear surtax on what was originally after-tax labor income. 
Solution. Putting together everything above, maximizing (1) is equivalent to maximizing

$$
\max _{c, \alpha} u(c)+\mathbf{E} v\left(R(w-c)+\alpha \tilde{z}+y_{0}+(1-\tau)\left(\bar{y}+\tilde{\epsilon}+\beta \tilde{z}-y_{0}\right)\right)
$$

To get to the heart of the mathematical structure of the problem, define $x=R w+y_{0}, \lambda=(1-\tau)$, $\theta=\alpha+(1-\tau) \beta$, and $\tilde{h}=\bar{y}-y_{0}+\tilde{\epsilon}$. Then (3) is equivalent to

$$
\max _{c, \theta} u(c)+\mathbf{E} v(x-R c+\lambda \tilde{h}+\theta \tilde{z})
$$

Define the pair of functions $C(x, \lambda)$ and $\Theta(x, \lambda)$ as the solution to $(4)-$

$$
(C(x, \lambda), \Theta(x, \lambda))=\arg \max _{(c, \theta)} u(c)+\mathbf{E} v(x-R c+\lambda \tilde{h}+\theta \tilde{z}) .
$$

Then the solution to (3) is given by

$$
c^{*}=C\left(R w+y_{0}, 1-\tau\right)
$$

and

$$
\alpha^{*}=\Theta\left(R w+y_{0}, 1-\tau\right)-(1-\tau) \beta
$$

Our goal is to analyze the effect of changes in the tax rate on $c^{*}$ and $\alpha^{*}$. Differentiating (7) (using subscripts for partial derivatives) reveals that

$$
\frac{d \alpha^{*}}{d \tau}=-\Theta_{\lambda}\left(R w+y_{0}, 1-\tau\right)+\beta
$$

Thus, the effect of increasing the tax rate $\tau$ on the amount of risky investment is always more positive when $\beta>0$ (there is a positive correlation between the returns on human capital and financial assets) than it is when $\beta=0$ (the returns on human capital and financial assets are independent). In other words, when $\beta>0$, any positive effect of labor income taxes on risky investment is enhanced. On the consumption side, (6) implies that

$$
\frac{d c^{*}}{d \tau}=-C_{\lambda}\left(R w+y_{0}, 1-\tau\right)
$$

so that $\beta$ does not alter the effect of the tax rate $\tau$ on consumption.

To make progress in evaluating $\frac{d \alpha^{*}}{d \tau}$ and $\frac{d c^{*}}{d \tau}$, we must analyze the functions $C(x, \lambda)$ and $\Theta(x, \lambda)$. We begin by imposing some structure on the first and second-period utility functions $u(\cdot)$ and $v(\cdot)$. First, we assume that $u(\cdot)$ and $v(\cdot)$ are both monotonically increasing, strictly concave functions (i.e., $u^{\prime}(\cdot)>0, v^{\prime}(\cdot)>0, u^{\prime \prime}(\cdot)<0$ and $\left.v^{\prime \prime}(\cdot)<0\right)$. Second, we assume that

$$
\frac{d}{d x}\left(\frac{-v^{\prime \prime}(x)}{v^{\prime}(x)}\right)<0
$$


that is, $v(\cdot)$ displays decreasing absolute risk aversion. This is a standard assumption that has a sound empirical basis because it is necessary for risky investment to be a normal good (to vary positively with wealth). Decreasing absolute risk aversion also insures that $v^{\prime \prime \prime}$ will be positivewhich implies a positive precautionary saving motive. Finally, we assume that

$$
\frac{d}{d x}\left(\frac{-\tilde{v}^{\prime \prime \prime}(x)}{v^{\prime \prime}(x)}\right)<0
$$

meaning that the precautionary saving motive decreases in strength with wealth. As shown in Kimball $(1990 \mathrm{a}, \mathrm{b}),-v^{\prime \prime \prime} / v^{\prime \prime}-$ or "absolute prudence"-measures the absolute strength of the precautionary saving motive, just as $-v^{\prime \prime} / v^{\prime}$ measures the absolute strength of risk aversion. Therefore, the assumption in (11) is simply that the absolute strength of the precautionary saving motive is decreasing in wealth ("decreasing absolute prudence"). This condition is plausible a priori, ${ }^{13}$ and is not very restrictive for utility functions that already exhibit decreasing absolute risk aversion, in the sense that almost all commonly used utility functions with decreasing absolute risk aversion also have decreasing absolute prudence. ${ }^{14}$ However, if one is trying, it is not difficult to construct a utility function that, over a certain range, satisfies (10) but not (11).

\section{The Effect of Labor Income Taxes on Saving and Portfolio Decisions}

We are now in a position to describe the effect of changes in the labor income tax rate on an individual's total saving and on an individual's saving in a risky financial asset. We do so by proving four propositions characterizing the functions $C(x, \lambda)$ and $\Theta(x, \lambda)$. Recall that $c$ is consumption in the first period; $x$ is the nonstochastic part of second-period wealth; $\lambda$ is 1 minus the future $\operatorname{tax}$ rate $\bar{\tau}$; and $\hat{\theta}$ equals the amount of explicit risky investment, $\alpha$, plus the implicit investment in the risky asset through human capital, $(1-\tau) \beta$.

Because first-period wealth is held constant, the change in total saving equals the opposite of any change in first-period consumption. Inferring changes in risky saving from changes in $\theta$ is more

13 See the arguments in Kimball (1990b), one of which is the following thought experiment: "Consider a college professor who has $\$ 10,000$ in the bank, and a Rockefeller who has a net worth of $\$ 10,000,000$, who have the same preferences except for their differences in initial wealth. If each is forced to face a coin toss at the beginning of the next year, with $\$ 5,000$ to be gained or lost depending on the outcome, which one will do more extra saving to be ready for the possibility of losing? If one's answer is that the college professor will do more extra saving, it argues for decreasing absolute prudence." More mechanically, Kimball (1990b) shows that absolute prudence is decreasing as long as the wealth elasticity of risk tolerance (which is always equal to 1 for constant relative risk aversion utility) does not increase too rapidly.

14 For example, all utility functions in the hyperbolic absolute risk aversion class that have (weakly) decreasing absolute risk aversion (such as constant relative risk aversion or constant absolute risk aversion utility functions) also have decreasing absolute prudence, and any mixture of utility functions that individually have decreasing absolute prudence also has decreasing absolute prudence. Quadratic utility has (weakly) decreasing absolute prudence but not the more basic property of decreasing absolute risk aversion. 
complicated, however, because risky saving equals $\theta$ minus $(1-\tau) \beta$. If the financial and human capital risks are uncorrelated $(\beta=0)$ the extra term disappears, and risky investment is measured by $\theta$. This is the principal case considered below. If the risks are positively correlated, our results are strengthened. In this case, a reduction in $\tau$ lowers risky investment both by reducing $\theta$ (as shown below) and by increasing the "after-tax beta" of human capital $(1-\tau) \beta$. If the risks are negatively correlated, a reduction in $\tau$ might increase risky investment (going against our story) because additional risky investment would be desirable to help insure against the increased human capital risk.

Which of these three cases is most likely? For most people, $\beta$ is probably close to zero. That is, their labor income risk is primarily idiosyncratic, and their financial risk is primarily aggregate. ${ }^{15}$ For entrepreneurs for whom the relevant risky investment is investment in their own company, $\beta$ will be strongly positive. Employees of brokerage houses or of firms in procyclical industries may also have a substantially positive $\beta$. Only for people with skills particularly appropriate for countercyclical industries (for example, bankruptcy lawyers) will $\beta$ be negative. Since we consider the case of negative $\beta$ atypical, but otherwise wish to be conservative, we concentrate on the case of $\beta=0$ to obtain a reasonable lower bound for the effect we are interested in.

We begin by considering the effects of an uncompensated change in future taxes; later we include the effects of an offsetting change in current taxes. Given the assumptions of monotonicity, concavity, decreasing absolute risk aversion and decreasing absolute prudence, one can prove the following four propositions about $C(x, \lambda)$ and $\Theta(x, \lambda)$. Proofs can be found in Appendices $A$ and $B$.

Proposition 1 says that both consumption and risky investment increase with wealth.

Proposition 1: If $u^{\prime}(\cdot)>0, u^{\prime \prime}(\cdot)<0, v^{\prime}(\cdot)>0, v^{\prime \prime}(\cdot)<0$, and $v(\cdot)$ exhibits decreasing absolute risk aversion, then

$$
C_{x}(x, \lambda)>0
$$

and

$$
\Theta_{x}(x, \lambda) \geq 0
$$

Proving (12) requires only monotonicity and concavity. Proving (13) requires monotonicity, concavity and decreasing absolute risk aversion. Neither (12) nor (13) depends on decreasing absolute prudence.

15 Recall that one of the justifications for the distinction between financial and human capital is the much greater difficulty in diversifying the latter. 
Proposition 1 implies that the wealth expansion path for $c$ and $\theta$ obtained by holding $\lambda$ fixed and varying $x$ is an upward-sloping line, as depicted in Figure 1. Proposition 2 implies that an increase in $\lambda$ shifts the wealth expansion path downward-toward lower $\theta$ for any given level of $c$. In words, Proposition 2 says that a decrease in the future tax rate shifts the consumer's optimum toward less risky investment for any given level of consumption. ${ }^{16}$

Proposition 2: If $u^{\prime}(\cdot)>0, u^{\prime \prime}(\cdot)<0, v^{\prime}(\cdot)>0, v^{\prime \prime}(\cdot)<0$, and $v(\cdot)$ exhibits decreasing absolute prudence, then

$$
\Theta_{x}(x, \lambda) C_{\lambda}(x, \lambda)-C_{x}(x, \lambda) \Theta_{\lambda}(x, \lambda) \geq 0
$$

As shown in Figure $1,\left(C_{x}, \Theta_{x}\right)$ is the vector along the wealth expansion path, and $\left(\Theta_{x},-C_{x}\right)$ is the downward perpendicular to that path. Therefore the expression in (14), $\Theta_{x} C_{\lambda}=C_{x} \Theta_{\lambda}$, is the dot product of $\left(C_{\lambda}, \Theta_{\lambda}\right)$ with the downward perpendicular to the wealth expansion path. Proposition 2 says that along with monotonicity and concavity, decreasing absolute prudence is enough to guarantee that the dot product is always positive. This means that an increase in $\lambda$ moves the point $(c, \theta)$ at an acute angle to the downward perpendicular to the wealth expansion path, and thus shifts the wealth expansion path down.

Note that the shift of the optimum toward less risky investment for any given level of consumption does not mean that an individual will always undertake less risky investment. If a decrease in the future tax rate results in a large enough increase in consumption, the individual's risky investment will increase as well. Consumption in turn is affected by two opposing forces-the increase in wealth due to the tax reduction tends to increase consumption, while the increased need for precautionary saving due to the increase in risk tends to decrease consumption.

The key here is the expected value of the individual's stochastic second-period wealth, $\tilde{h}=$ $\bar{y}-y_{0}+\tilde{\epsilon}$, to which the tax is applied. If $\mathbf{E} \tilde{h}$ is very large, then a reduction in the tax rate produces a large enough rise in expected after-tax income to override both the precautionary saving effect and the risk crowding effect, thus raising both consumption and investment in the risky asset. If $\mathbf{E} \tilde{h}$ is somewhat smaller, then a reduction in the tax rate produces a large enough rise in expected after-tax income to override the precautionary saving effect and raise consumption, but not enough to override the risk crowding effect and raise risky investment. And even smaller values of $\mathbf{E} \tilde{h}$ mean that a reduction in the tax rate lowers both consumption and risky investment. Proposition

16 The simple statement here is for $\hat{\beta}=\overline{0}$. If $\hat{\beta}>\hat{0}$, the level of risky investment that goes along with any given level of consumption will fall even more with a reduction in the tax rate $\tau$. If $\beta<0$, the level of risky investment that goes along with any given level of consumption may rise with a reduction in the tax rate since risky investment would provide insurance for the additional human capital risk. 
4 below characterizes the effect of taxes on consumption.

Proposition 3 is closely related to Proposition 2. To explain the connection, it is helpful first to view Proposition 2 as saying that an increase in labor income risk and return that leaves precautionary saving unchanged still causes a reduction in the amount of an independent financial risk which is borne. In other words, the negative interaction between independent risks-termed "temperance" by Kimball (1992) - is stronger than the precautionary saving motive. This parallels Drèze and Modigliani's (1972) finding that an increase in risk that leaves utility unchanged still causes an increase in the amount of precautionary saving. Kimball (1992) summarizes these results by writing that "just as decreasing absolute risk aversion implies that prudence is greater than risk aversion, decreasing absolute prudence implies that temperance is greater than prudence."

If decreasing absolute prudence makes temperance stronger than prudence, and decreasing absolute risk aversion makes prudence stronger than risk aversion, then the combination of decreasing absolute prudence and decreasing absolute risk aversion should imply that temperance is stronger than risk aversion. In particular, Proposition 3 shows that, given decreasing absolute risk aversion and decreasing absolute prudence, even a compensated increase in independent labor income risk to which an individual is indifferent leads to a reduction in independent risky investment. ${ }^{17} \mathrm{~A}$ fortiori, any increase in independent labor income risk that is not compensated enough to make the individual indifferent leads to a reduction in independent risky investment.

Proposition 3: If $u^{\prime}(\cdot)>0, u^{\prime \prime}(\cdot)<0, v^{\prime}(\cdot)>0, v^{\prime \prime}(\cdot)<0, v(\cdot)$ exhibits decreasing absolute risk aversion and decreasing absolute prudence, and

$$
\left.\frac{\partial}{\partial \lambda}(u(c)+\mathbf{E} v(x-R c+\theta \tilde{z}+\lambda \tilde{h}))\right|_{(c, \theta)=(C(x, \lambda), \Theta(x, \lambda))} \leq 0
$$

then

$$
\Theta_{\lambda}(x, \lambda) \leq 0
$$

This result is exactly what is required to analyze equation (8) above. An increase in $\lambda$ represents a decrease in the future tax rate and thus an increase in labor income risk. With no change in lump-sum taxes, it also represents an increase in wealth, and the combination of increased risk and increased wealth may raise or lower utility. So, in what situations will condition (15) hold? Clearly,

17 Pratt and Zeckhauser (1987) note that -under their assumptions, if a new insurance policy comes into the market, anyone who voluntarily purchases the policy wili do more of other risky investment. Proposition 3 says that the combination of decreasing absolute prudence and decreasing absolute risk aversion is enough to guarantee that result even when the consumption/saving decision is integrated with the portfolio composition decision. 
the precise nature of preferences plays an important role. For a given change in taxes, someone with greater risk aversion is more likely to suffer a decline in utility and thus do less risky financial investment than someone with a greater tolerance for risk. But there is no straightforward way to characterize the restrictions on preferences that would be sufficient to guarantee condition (15) for any possible tax change. Therefore, we try instead to characterize the types of tax changes that would satisfy condition (15) for any preferences that meet our existing assumptions. We start with the ambiguous implication for utility of a decrease in the future tax rate combined with no change in lump-sum taxes. This means that a utility-compensating change in lump-sum taxes might be either an increase or a decrease. But an increase in lump-sum taxes large enough to leave expected tax payments unchanged would have no wealth effect and thus unambiguously lower utility. In other words, the set of inadequately compensated changes in labor income risk necessarily includes tax changes that are intertemporally revenue-neutral. ${ }^{18}$

What kinds of tax changes will be revenue-neutral? The answer depends on the interpretation given to the model's risky financial asset. Consider first the case where the risky financial asset embodies the aggregate financial risk in the economy. Then a tax change is revenue-neutral if and only if $y_{0}=\bar{y}$, or equivalently, iff $\mathbf{E} \tilde{h}=\mathbf{E} \tilde{\epsilon}=0$. Tax revenue is not affected by idiosyncratic labor income risk because of the law of large numbers. ${ }^{19}$ Tax revenue may appear to be a function of the financial risk taken by individuals, except that the government can offset any change in its financial risk-bearing through other actions in the financial market. If the government does use the financial market to offset changes in its financial risk-bearing, or if taxpayers consider government risk-bearing as if it were their own risk-bearing (as they should if the government eventually absorbs the financial risk it bears through stochastic lump-sum taxes), then the change in national financial risk-bearing is given directly by the change in $\theta$. In this case, the defining characteristic of a revenue-neutral tax change is that it does not affect the expected present value of the part of labor income remaining after any implicit investment in the risky financial asset is removed.

Now consider the case where the risky financial asset represents idiosyncratic projects for which private information prevents adequate diversification of returns. Then a small tax change is revenue-neutral if and only if

$$
y_{0}=\mathbf{E} \tilde{y}=\bar{y}+\left(\beta+\alpha^{*}\right) \mathbf{E} \tilde{z}=\bar{y}+\theta^{*} \mathbf{E} \tilde{z}
$$

18 Remember that the model implies Ricardian equivalence for lump-sum taxes, so the timing of lump-sum taxes is irrelevant.

19 Aggregate labor income risk will still affect both individual incomes and government revenue. Because the government cannot insure individuals against this risk through redistributive taxes, we do not focus on it here. 
or equivalently, iff

$$
\mathbf{E} \tilde{h}=\mathbf{E}\left[\bar{y}-y_{0}+\tilde{\epsilon}\right]=-\theta^{*} \mathbf{E} \tilde{z} \leq 0 .
$$

In this second case, the effects on government revenue of both idiosyncratic labor income and financial risks are canceled out by the law of large numbers. The inequality $-\hat{\theta}^{*} \mathbf{E} \tilde{z} \leq 0$ follows from the fact that the optimal exposure to a risk is always of the same sign as its expected value. Since in this case taxes help to diversify financial as well as nonfinancial risks, taxes are more valuable than in the first case where the risky asset represents aggregate financial risk. Thus, a revenue-neutral reduction in the tax rate is even less desirable to individuals here than in the first case, so that Proposition 3 can be applied.

On either interpretation of the financial risky asset, therefore, the following corollary to Proposition 3 effectively guarantees that an intertemporally revenue-neutral reduction in the future tax rate leads to a reduction in financial risk-bearing.

Corollary 3.1: If $u^{\prime}(\cdot)>0, u^{\prime \prime}(\cdot)<0, v^{\prime}(\cdot)>0$, $v^{\prime \prime}(\cdot)<0, v(\cdot)$ exhibits decreasing absolute risk aversion and decreasing absolute prudence, and $\mathbf{E} \tilde{h} \leq 0$, then $\Theta_{\lambda}(x, \lambda) \leq 0$.

Intertemporally revenue-neutral tax changes include changes in the timing of income taxes like those discussed by Barsky, Mankiw and Zeldes (1986) and Kimball and Mankiw (1989). By Corollary 3.1, a postponement of labor income taxes-which appears here as an increase in $\tau$ and a reduction in $\lambda$-crowds in risky investment.

To review, Proposition 3 says that a decrease in the future tax rate causes an individual to do less risky saving as long as the individual is not made better off by the tax change. It might appear that a similarly strong result could be derived about the effect of such a tax change on consumption and total saving, but unfortunately this is not the case.

This lack of a clear result is surprising, because the effect on the consumption/saving decision of an increase in labor income risk in the absence of an additional risky investment choice is settled by Leland (1968), Rothschild and Stiglitz (1971), and Drèze and Modigliani (1972). In that setting Leland (1968) shows that a single mean-zero risk leads to reduced consumption as long as $u^{\prime \prime \prime}>0$. Rothschild and Stiglitz extend Leland's result to mean-preserving spreads. Drèze and Modigliani show that any undesirable risk or undesirable increase in the scale of a risk leads to reduced consumption as long as absolute risk aversion is decreasing. This result indicates that in the absence of an additional risky investment choice, a decrease in the labor income tax rate that does not make the individual better off will lead to less consumption and more saving. 
What complicates the analysis of the precautionary saving effect in our model is the interaction of the labor income risk and the financial asset risk. The direct effect of an imposed increase in human capital risk is still to increase saving through the basic precautionary motive. But in the situation we model there is an indirect effect as well: the induced decrease in financial capital risk tends to decrease saving through the same precautionary motive. The induced decrease in financial capital risk is sometimes large enough to reduce the overall riskiness of the individual's future income, and thus lead to a net reduction in precautionary saving. Thus, our main result about the effect of human capital risk on other risk-taking creates ambiguity about the effect of human capital risk on total saving.

Appendix B provides a numerical counterexample to the idea that greater human capital risk must lead to less first-period consumption and more saving. The counterexample has a utility function with decreasing absolute risk aversion and decreasing absolute prudence. For the parameter values chosen, even a mean-preserving scaling-up of human capital risk increases consumption and reduces saving through a strong negative effect on financial risk-taking. Appendix $B$ also shows that an increase in the mean of future labor income to compensate for the effect of the increased risk on utility would reduce saving even more.

Thus, without further assumptions, one cannot prove that a scaling-up of human capital risk raises saving. Yet, it seems appropriate to expect the direct effect to outweigh the indirect effect in most circumstances. Can we identify some circumstances in which this will be true? In particular, when can we be sure that a decrease in the future tax rate that does not make an individual better off will increase total saving? By a mathematical connection, this question is equivalent to the question of when two assets whose quantities can be freely varied will both be normal goods. Proposition 4 says that an individual will save more in response to an unpleasant tax change whenever human capital would be a normal good if its quantity could be freely varied.

Proposition 4: If $u^{\prime}(\cdot)>0, u^{\prime \prime}(\cdot)<0, v^{\prime}(\cdot)>0, v^{\prime \prime}(\cdot)<0$ and

$$
\left.\frac{\partial}{\partial \lambda}(u(c)+\mathbf{E} v(x-\underline{R} c+\theta \tilde{z}+\lambda \tilde{h}))\right|_{(c, \theta)=(C(x, \lambda), \Theta(x, \lambda))}=0,
$$

then $C_{\lambda}(x, \lambda) \leq 0$ if and only if the optimal choice of $\lambda$ would have a positive wealth elasticity at $(x, \lambda)$.

Our two-period model assumes thãt individuals cannot change the amount of human capital that they hold. If they could vary this amount, however, the changes in human capital risk that result would be structurally equivalent to changes in $(1-\tau)$, which equals $\lambda$. Thus, condition 
(17) says that the amount of human capital risk (captured by $\lambda$ ) is optimal given the individual's optimal choices of $c$ and $\theta$. Using notation defined in Appendix A, Proposition 4 says that if the agent is indifferent to a marginal change in $\lambda$, then

$$
\operatorname{sign}\left(C_{\lambda}\right)=-\operatorname{sign}\left(\frac{d \lambda^{*}}{d x}\right) .
$$

This result is exactly what is required to analyze equation (9) above. The economic logic underlying Proposition 4 is a link between two aspects of individual behavior. One aspect of behavior-the one we are concerned about here-is the effect on saving of an expected-utilitypreserving increase in labor income risk when the amount of risky financial capital can be chosen as well. The other aspect of behavior - the one that is the basis for the proposition-is the effect of wealth on the optimal amount of risky human capital in a standard portfolio problem with another risky asset. Although these two effects may appear to be distinct, they are fundamentally the same. The first effect is the change in saving that results from an exogenous change in human capital risk, while the second effect is the change in human capital risk that results from an exogenous change in wealth (and thus, saving). In both cases, the direct effect is a positive relationship: an increase in risk will tend to raise saving, and an increase in wealth and saving will encourage more risktaking. ${ }^{20}$ But in both cases there is an offsetting, indirect effect that arises from the individual's ability to vary another type of risk, namely financial risk. ${ }^{21}$

The intuition for this indirect effect in the first case is discussed above. The intuition in the second case is straightforward: the direct effect of extra saving on investment in the risky financial asset is positive, and the greater uncertainty about future income that this choice creates will discourage investment in other risky assets, like human capital. Thus, in both cases the crucial issue is the complementarity (or substitutability) of human capital risk and saving in the face of endogenous adjustment of financial risk. This complementarity or substitutability is symmetric across these two cases, which makes the condition in Proposition 4 a logical condition for the problem we are interested in.

Proposition 4 has two corollaries. ${ }^{22}$ First, suppose that the second-period utility function displays constant relative risk aversion, perhaps with a displaced origin; that is, suppose that $v$

20 This relationship is guaranteed by the assumption of decreasing absolute risk aversion; see Kimball (1992).

$21 \beta$ has no effect on the wealth elasticity of human capital, since optimal adjustment of financial asset holdings cancels out any undesired changes in financial risk-bearing implicit in changes in human capital holdings. Therefore, one can assume without loss of generality that human capital and the financial asset have independent returns.

22 As an aside, there is also one implausible set of assumptions that would guarantee normality of both risks and therefore that an undesirable increase in human capital risk would lead to more saving: the combination of increasing absolute prudence and decreasing absolute risk aversion. Increasing abolute prudence, by implying 
is in the hyberbolic absolute risk aversion class and has decreasing absolute risk aversion. Then, increases in wealth lead to equiproportionate increases in holdings of the risky assets, ensuring that both risky assets are normal. ${ }^{23}$ Thus, by Proposition 4, constant relative risk aversion implies that any undesirable increase in labor income risk leads to a reduction in first-period consumption and an increase in saving:

Corollary 4.1: If $u^{\prime}(\cdot)>0, u^{\prime \prime}(\cdot)<0, v$ is of the form $v(x)=\frac{\left(x-x_{0}\right)^{1-\gamma}}{1-\gamma}$, defined for $x>x_{0}$, with $\gamma>0$ (with $v(x)=\ln \left(x-x_{0}\right)$ for $\gamma=1$ ), and

$$
\left.\frac{\partial}{\partial \lambda}(u(c)+\mathbf{E} v(x-R c+\theta \tilde{z}+\lambda \tilde{h}))\right|_{(c, \theta)=(C(x, \lambda), \Theta(x, \lambda))} \leq 0,
$$

then $C_{\lambda}(x, \lambda) \leq 0$.

Second, suppose that one of the two risks has a two-point distribution. Given decreasing absolute risk aversion, the other risk will be normal (a result that is new with this paper). Thus, by Proposition 4, if the risky financial asset has a two-point distribution, any undesirable increase in labor income risk leads to a reduction in first-period consumption and an increase in saving:

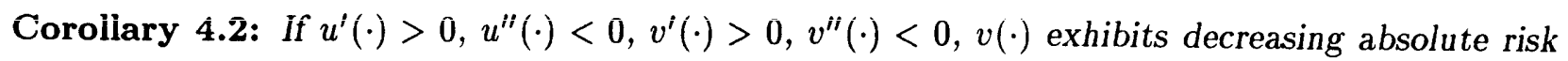
aversion, $\tilde{z}$ is a two-point risk, and

$$
\left.\frac{\partial}{\partial \lambda}(u(c)+\mathbf{E} v(x-R c+\theta \tilde{z}+\lambda \tilde{h}))\right|_{(c, \theta)=(C(x, \lambda), \Theta(x, \lambda))} \leq 0,
$$

then $C_{\lambda}(x, \lambda) \leq 0$.

In summary, it still appears somewhat likely that an undesirable increase in human capital risk will reduce first-period consumption and raise saving. Yet, if the financial risk has more than a two-point distribution and the utility function does not exhibit constant relative risk aversion, it is possible for an undesirable increase in human capital risk to raise first-period consumption and lower saving. ${ }^{24}$

complementarity between two independent assets, would guarantee that the optimal quantities of the two assets would go up and down together and so guarantee positive wealth elasticities. Even beyond the arguments given above for decreasing absolute prudence, these assumptions are an implausible combination: given monotonicity, concavity, and the Inada condition at infinity $\left(a^{\prime}(\infty)=0\right)$, globally increasing absolute prudence implies globally increasing absolute risk aversion (as one can see by reversing the direction of the proof in Kimball (1993, Appendix B)).

$\overline{2} \overline{3}$ In this vein, Hart (1975) shows that conditions stringent enough to guarantee that the mix of risky securities does not depend on wealth, together with decreasing absolute risk aversion, guarantee a positive wealth elasticity for every security.

24 Indeed, the numerical counterexample in Appendix B involves only a three-point distribution for the financial 


\section{A Numerical Illustration}

Several of the results in the previous section indicate that the effect of human capital risk on financial risk-taking can be substantial. Proposition 2 shows that this effect is at least as strong as the effect of human capital risk on consumption, while Proposition 3 shows that the effect is at least as strong as the effect of human capital risk on utility. Thus, these results imply that changes in taxes that reduce labor income risk can have a noticeable effect on financial risk-taking. To provide more direct evidence on the magnitude of this effect, we present the following simple numerical illustration.

We interpret our model as a life-cycle model, with each period lasting one generation. Let the utility function be

$$
U=.5\left[\ln \left(c_{1}\right)+E \ln \left(\tilde{c}_{2}\right)\right]
$$

set the real interest rate to zero, and normalize initial resources to 2 . The factor of .5 on the utility function means that a 1 percent increase in overall resources produces a .01 increase in utility. In the absence of human capital risk and any financial risk-taking opportunities, the individual woüld choose to consume 1 in each period, and would achieve a total utility of 0 .

Now introduce a financial risk-taking opportunity. Suppose that borrowing one unit to invest in the risky asset has an equal chance of yielding .5 or -.25 ; that is, $\tilde{z}=.5$ with probability onehalf and -.25 with probability one-half. It is easy to calculate that in the absence of any human capital risk, the agent will continue to consume 1 in the first period and invest 1 in the risky asset. Consumption in the second period will be 1.5 or .75 with equal probability, and expected utility will be .03 .

Finally, we add human capital risk, with a mean-zero symmetric two-point distribution, whose standard deviation after taxes is $(1-\tau) \sigma_{y}$. Table 1 shows optimal values of $\theta, c$, and $U$ for values of $(1-\tau) \sigma_{y}$ between 0 and 1 . Note that $\theta, c$, and $U$ are measured in comparable units, with a difference of .01 representing the effect of a 1 percent change in scale. ${ }^{25}$ Table 1 confirms the implication of our propositions that the effect of human capital risk on risky investment is greater

risk, a small mean-zero human capital risk, and a utility function that is the sum of two logarithmic utility functions with different origins, so there is not much room to strengthen Corollaries 4.1 and 4.2 . Note that a utility function that is the sum of two logarithmic utility functions could arise as a reduced form from an underlying logarithmic utility function with a third background risk. Thus, there is no way to extend Corollary 4.1 to allow for such a third (exogenous) risk. Corollary 4.2 can readily be extended to such a situation, since the financial risk would still have a two-point distribution, and decreasing absolute risk aversion is unaltered by a background risk.

25 This statement is always true for $U$, and is true for $\theta$ and $c$ when they are near 1. Taking logarithms of $\theta$ and $c$ would make the comparison more exact. 
than its effect on consumption, which is in turn greater than its effect on utility.

$\begin{array}{cccc}(1-\tau) \sigma_{y} & \theta & c & U \\ 0 & 1 & 1 & .03 \\ .1 & .99 & .99 & .03 \\ .2 & .95 & .98 & .02 \\ .3 & .89 & .95 & .00 \\ .4 & .82 & .92 & -.01 \\ .5 & .75 & .88 & -.04 \\ .6 & .68 & .84 & -.07 \\ .7 & .61 & .79 & -.10 \\ .8 & .54 & .74 & -.14 \\ .3 & .48 & .69 & -.19 \\ 1.0 & .42 & .63 & -.24\end{array}$

If the standard deviation of future labor income is .5 (within the range studied by Barsky, Mankiw and Zeldes (1986)), then raising the future marginal tax rate from 0 to 20 percent causes $(1-\tau) \sigma_{y}$ to decline from .5 to .4. Table 1 shows that this 20 percentage point increase in the tax rate produces close to a 10 percent increase in risky investment (from .75 to .82 ). Thus, the semi-elasticity of risky investment with respect to the future tax rate is roughly one-half. A 20 percentage point increase in the tax rate from 20 percent to 40 percent produces an 8 percent increase in risky investment (from .82 to .89 ), for a semi-elasticity of roughly two-fifths.

The size of this effect is sensitive to the amount of human capital risk, as one would expect. If the standard deviation of future labor income is .4, for example, then an increase in the future marginal tax rate from 0 to $25 \%$ produces an 8 percent increase in risky investment, for a semielasticity of roughly one-third. As human capital risk declines further, the semi-elasticity of risky investment with respect to the tax rate declines as well.

There is also some direct empirical evidence that the effect of human capital risk on financial risk-taking can be substantial. Guiso, Jappelli, and Terlizzese (1994) study the portfolio choices of Italian households using the Survey of Income and Wealth. Their estimates suggest that the elimination of income uncertainty would increase the portfolio share of risky assets by 2 to 14 percentage points (Tables 5 and 7 ).

\section{Conclusion}

Individuals' ability to earn labor income is often their most valuable asset; but this asset carries with it a large and mostly unmarketable risk. A decrease in current taxes combined with an offsetting future increase in proportional or progressive labor income taxes provides insurance 
against this risk. (And because most labor income risk is idiosyncratic, individual uncertainty can be reduced with no increase in the uncertainty of government revenue.) Barsky, Mankiw and Zeldes (1986) show that the reduction in idiosyncratic labor income risk acts through the precautionary saving motive to reduce saving relative to a Ricardian benchmark. In this paper we show that the reduction in idiosyncratic labor income risk affects portfolio decisions as well.

We analyze the effect of labor income risk on the joint saving/portfolio-composition decision in a two-period model. We show that, given plausible restrictions on preferences, any change in taxes that reduces an individual's labor income risk and does not make her worse off will lead her to invest more in a risky security, even if its return is statistically independent of the labor income risk. A deferral of labor income taxes with no change in their expected present value is one such tax change.

An additional curious result is that the effect of labor income risk on portfolio composition can be so powerful that consequent indirect effects overturn the usual positive effect of labor income risk on overall saving that is familiar from the precautionary saving literature. Ruling out this possibility requires relatively strict assumptions, such as constant relative risk aversion or a twopoint distribution for the return on the financial asset. This counterintuitive result turns out to be related to the difficulty of guaranteeing that a pair of independent risks will both be normal goods.

One implication of our results concerns the effect of government debt issuance on risky investment. Suppose that the government reduces taxes today and raises taxes in the future, although not necessarily by a corresponding amount. The results in Section III imply that this increase in government debt will crowd in risky investment whenever any of the following conditions is satisfied:

(1) the expected present value of taxes faced by an individual is unchanged-i.e., there is a change only in the timing of taxes (Corollary 3.1 );

(2) the increased future taxes have a strong enough insurance effect that the policy raises expected utility (Proposition 3); or

(3) the tax changes lead to higher current consumption (Proposition 2).

Thus we concur with Friedman (1978) that crowding in will occur when the government reduces taxes now and pays off the debt with higher taxes in the future. ${ }^{26}$ But our results are based on

26 Frankel (1985) estimates that portfolio effects on rates of return are very small, but that crowding in of equity investment is more likely than crowding out. We can foresee two ways in which an empirical analysis based on ouir approach would differ from Frankel's. First, Frankel does not ailow for the effects of future tax liabilities, which play an important role in our analysis. Second, Frankel constrains government debt to affect asset demands only through changes in the market portfolio, and therefore through the covariances of asset returns with the market portfolio. In our approach, the risk aversion of the indirect utility function depends on expected future tax rates; therefore, changing those rates changes the market risk premium. 
a neoclassical foundation of expected utility maximization in the absence of complete insurance markets. Moreover, individuals in our model are fully aware of their future tax liabilities, which allows us to show that financial crowding in can coexist with Ricardian equivalence of lump-sum tax reschedulings.

Thus, our analysis establishes clear results about the effect of labor income risk on investment in other risky assets, ${ }^{27}$ but casts some doubt on the generality of previous results about the effect of labor income risk on total saving. ${ }^{28}$

27 It may be surprising that we can establish such clear results about labor income taxes and financial risk-taking when the literature on capital income taxes and financial risk-taking is replete with ambiguities. The main explanation for the difference is that individuals cannot trade away their risky human capital in the way that they can trade away risky financial assets.

28 One direction for further research is to extend our results to models with more than two periods. Kimball $(1990 \mathrm{~b})$ gives one idea of how this might be done. In a multiperiod model, the absolute risk aversion of the value function is equal to the product of the absolute risk aversion of the underlying period utility function and the marginal propensity to consume out of wealth. Under conditions similar to those we assume, idiosyncratic labor income risk raises the absolute risk aversion of the value function both by raising the marginal propensity to consume out of wealth and by raising the absolute risk aversion of the underlying period utility function through lowering consumption. Equivalently, Breeden (1986) finds that for continuous-time diffusion processes, the expected rate of return differential between risky and riskless securities should be equal to the product of an agent's underlying risk aversion and the covariance of the rate of return differential with consumption growth. Grossman and Shiller (1982) show that this relationship can be aggregated: the market risk premium should be equal to the product of a weighted average of agents' underlying risk aversions and the covariance between the rate of return differential and aggregate consumption growth. Idiosyncratic labor income risk raises the premium for holding risky assets in two ways: by lowering consumption, and therefore underlying risk aversion, and by raising the marginal propensity to consume out of wealth and therefore the covariance of consumption with the returns on risky securities in which agents have substantial positions. 


\section{Appendix A}

\section{Proofs of Propositions 1-3}

Five lemmas prepare the ground for proofs of Propositions 1-3. Define

$$
J(c, \theta ; x, \lambda)=u(c)+\mathbf{E} v(x-R c+\lambda \tilde{h}+\theta \tilde{z}) .
$$

Then

$$
(C(x, \lambda), \Theta(x, \lambda))=\arg \max _{c, \theta} J(c, \theta ; x, \lambda) .
$$

Lemmas 1-5 characterize the function $J$. All of the results here assume that the risks $\tilde{z}$ and $\tilde{h}$ are nondegenerate and statistically independent of each other and that $u^{\prime}(\cdot)>0, u^{\prime \prime}(\cdot)<0, v^{\prime}(\cdot)>0$, $v^{\prime \prime}(\cdot)<0$. Lemmas 3 and 4 rely in addition on $v$ having decreasing absolute risk aversion. Lemma 5 relies on $v$ having decreasing absolute prudence, but does not rely on decreasing absolute risk aversion. Subscripts denote partial derivatives.

Lemma 1: For all $c, \theta, x$ and $\lambda$,

$$
\begin{gathered}
J_{c c}(c, \theta ; x, \lambda)=R^{2} J_{x x}(c, \theta ; x, \lambda)+u^{\prime \prime}(c), \\
J_{c \theta}(c, \theta ; x, \lambda)=-R J_{x \theta}(c, \theta ; x, \lambda), \\
J_{c x}(c, \theta ; x, \lambda)=-R J_{x x}(c, \theta ; x, \lambda), \\
J_{c \lambda}(c, \theta ; x, \lambda)=-R J_{x \lambda}(c, \theta ; x, \lambda), \\
J_{\theta \theta}<0
\end{gathered}
$$

and

$$
J_{\lambda \lambda}<0 .
$$

Proof. Differentiate (A.1).a

Lemma 2: For all $c, \theta, x$ and $\lambda$,

$$
\begin{gathered}
J_{c c} J_{\theta \theta}-J_{c \theta}^{2}>R^{2}\left[J_{x x} J_{\theta \theta}-J_{\theta x}^{2}\right]>0 \\
J_{c c} J_{\lambda \lambda}-J_{c \lambda}^{2}>R^{2}\left[J_{x x} J_{\lambda \lambda}-J_{x \lambda}^{2}\right]>0 \\
J_{c c} J_{x x}-J_{c x}^{2}>0
\end{gathered}
$$


and

$$
J_{\theta \theta} J_{\lambda \lambda}-J_{\theta \lambda}^{2}>0
$$

Proof. Any sum of concave functions and any expectation over concave functions is concave. Since both $u$ and $v$ are jointly concave in all $c, \theta, x, \lambda$ for particular realizations of $\tilde{z}$ and $\tilde{h}$, the function $J$ is jointly concave in all four arguments. The strict inequalities follow from $u^{\prime \prime}(\cdot)<0, v^{\prime \prime}(\cdot)<0$, (A.7), (A.8) and from the nondegeneracy and independence of $\tilde{z}$ and $\tilde{h} .{ }^{29}$

Lemma 3: For any random variable $\tilde{q}$, the derived utility function

$$
\hat{v}(x)=\mathbf{E} v(x+\tilde{q})
$$

inherits decreasing absolute risk aversion from $v$.

Proof. Both Nachman (1982) and Kihlstrom, Romer and Williams (1981) give proofs of Lemma 3. Since decreasing absolute risk aversion is equivalent to convexity of $\ln \left(v^{\prime}(x)\right)$, Lemma 3 is a consequence of Artin's 1931 Theorem that log-convexity is preserved under expectations. Marshall and Olkin (1979) give a particularly simple proof of Artin's theorem based on the fact that any sum of or expectation over positive semidefinite matrices is positive semidefinite. Decreasing absolute risk aversion of $v$ implies convexity of $\ln \left(v^{\prime}(x+\tilde{q})\right)$ for each realization of $\tilde{q}$, which is equivalent to positive semidefiniteness of the matrix

$$
\left[\begin{array}{cc}
v^{\prime}(x+\tilde{q}) & v^{\prime}(x+\tilde{q}+\delta) \\
v^{\prime}(x+\tilde{q}+\delta) & v^{\prime}(x+q+2 \delta)
\end{array}\right]
$$

This implies positive definiteness of

$$
\left[\begin{array}{cc}
\mathbf{E} v^{\prime}(x+\tilde{q}) & \mathbf{E} v^{\prime}(x+\tilde{q}+\delta) \\
\mathbf{E} v^{\prime}(x+\tilde{q}+\delta) & \mathbf{E} v^{\prime}(x+\tilde{q}+2 \delta)
\end{array}\right]
$$

and decreasing absolute risk aversion for $\hat{v}(\cdot)$.

Lemma 4: If $\theta \geq 0$, then $J_{\theta x}(c, \theta ; x, \lambda) \geq 0$ wherever $J_{\theta}(c, \theta ; x, \lambda) \leq 0$. Similarly, if $\lambda \geq 0$, then $J_{\lambda x}(c, \theta ; x, \lambda) \geq 0$ wherever $J_{\lambda}(c, \theta ; x, \lambda) \leq 0$.

Proof. By the symmetry between $\theta$ and $\lambda$ in the definition of $J$ (A.1), proving one half of Lemma 4 is enough to prove both halves. Letting $\tilde{q}=\lambda \tilde{h}-R c$ in (A.13),

$$
J_{\theta}(c, \theta ; x, \lambda)=\mathbf{E} \tilde{z} v^{\prime}(x-R c+\theta \tilde{z}+\lambda \tilde{h})=\mathbf{E} \tilde{z} \hat{v}^{\prime}(x+\theta \tilde{z})
$$

29 The Cauchy-Schwartz inequalities which apply to the expanded versions of (A.9-A.12) hold with equality only when the random variables are perfectly correlated or when one of the random variables is degenerate. 
and

$$
J_{\theta x}(c, \theta ; x, \lambda)=\mathrm{E} \tilde{z} v^{\prime \prime}(x-R c+\theta \tilde{z}+\lambda \tilde{h})=\mathrm{E} \tilde{z} \hat{v}^{\prime \prime}(x+\theta \tilde{z})
$$

because of the independence of $\tilde{z}$ and $\tilde{h}$. Decreasing absolute risk aversion of $\hat{v}$ makes $\frac{\hat{v}^{\prime \prime}(x+\theta \tilde{z})}{\hat{v}^{\prime}(x+\theta \bar{z})}$ an increasing function of $\tilde{z}$, so that

$$
\frac{\hat{v}^{\prime \prime}(x+\theta \tilde{z})}{\hat{v}^{\prime}(x+\theta \tilde{z})}-\frac{\hat{v}^{\prime \prime}(x)}{\hat{v}^{\prime}(x)}
$$

has the same sign as $\tilde{z}$. Thus,

$$
J_{\theta}(c, \theta ; x, \lambda)=\mathbf{E} \tilde{z} \hat{v}^{\prime}(x+\theta \tilde{z}) \leq 0
$$

implies

$$
\begin{aligned}
J_{\theta x}(c, \theta ; x, \lambda) & =\mathbf{E} \tilde{z} \hat{v}^{\prime \prime}(x+\theta \tilde{z}) \\
& \geq \mathbf{E} \tilde{z} \hat{v}^{\prime \prime}(x+\theta \tilde{z})-\frac{\hat{v}^{\prime \prime}(x)}{\hat{v}^{\prime}(x)} \mathbf{E} \tilde{z} \hat{v}^{\prime}(x+\theta \tilde{z}) \\
& =\mathbf{E} \tilde{z}\left[\frac{\hat{v}^{\prime \prime}(x+\theta \tilde{z})}{\hat{v}^{\prime}(x+\theta \tilde{z})}-\frac{\hat{v}^{\prime \prime}(x)}{\hat{v}^{\prime}(x)}\right] \hat{v}^{\prime}(x+\theta \tilde{z}) \\
& \geq 0 .
\end{aligned}
$$

Lemma 5: For any $c, x, \theta \leq 0$ and $\lambda \geq 0$,

$$
J_{\theta \lambda}(c, \theta ; x, \lambda) J_{x x}(c, \theta ; x, \lambda)-J_{\theta x}(c, \theta ; x, \lambda) J_{\lambda x}(c, \theta ; x, \lambda) \geq 0
$$

Proof. Decreasing absolute prudence is equivalent to convexity of $\ln \left(-v^{\prime \prime}\right)$. Therefore, for any four quantities $z_{1}, z_{2}, h_{1}$ and $h_{2}$;

$\ln \left(-v^{\prime \prime}\left(x+\theta z_{1}+\lambda h_{1}\right)\right)+\ln \left(-v^{\prime \prime}\left(x+\theta z_{2}+\lambda h_{2}\right)\right) \geq \ln \left(-v^{\prime \prime}\left(x+\theta z_{1}+\lambda h_{2}\right)\right)+\ln \left(-v^{\prime \prime}\left(x+\theta z_{2}+\lambda h_{1}\right)\right)$

when $\left(z_{2}-z_{1}\right)\left(h_{2}-h_{1}\right) \geq 0$, with the direction of the inequality in (A.21) reversed when $\left(z_{2}-z_{1}\right)\left(h_{2}-h_{1}\right) \leq 0$. Exponentiating both sides of (A.21) and subtracting, the quantity

$$
v^{\prime \prime}\left(x+\theta z_{1}+\lambda h_{1}\right) v^{\prime \prime}\left(x+\theta z_{2}+\lambda h_{2}\right)-v^{\prime \prime}\left(x+\theta z_{1}+\lambda h_{2}\right) v^{\prime \prime}\left(x+\theta z_{2}+\lambda h_{1}\right)
$$

always has the same sign as $\left(z_{2}-z_{1}\right)\left(h_{2}-h_{1}\right)$. Thus, if $\tilde{z}_{1}, \tilde{z}_{2}, \tilde{h}_{1}$ and $\tilde{h}_{2}$ are mutually independent random variables with $\tilde{z}_{1}$ and $\tilde{z}_{2}$ having the same distribution as $\tilde{z}$, and $\tilde{h}_{1}$ and $\tilde{h}_{2}$ having the same distribution as $\tilde{h}$, then 


$$
\begin{aligned}
J_{\theta \lambda}(c, \theta ; x, \lambda) J_{x x}(c, \theta ; x, \lambda)-J_{\theta x}(c, \theta ; x, \lambda) J_{\lambda x}(c, \theta ; x, \lambda) & \\
& =\left\{\mathbf{E} \tilde{z} \tilde{h} v^{\prime \prime}(x+\theta \tilde{z}+\lambda \tilde{h})\right\}\left\{\mathbf{E} v^{\prime \prime}(x+\theta \tilde{z}+\lambda \tilde{h})\right\} \\
& -\left\{\mathbf{E} \tilde{z} v^{\prime \prime}(x+\theta \tilde{z}+\lambda \tilde{h})\right\}\left\{\mathbf{E} \tilde{h} v^{\prime \prime}(x+\theta \tilde{z}+\lambda \tilde{h})\right\} \\
& =\frac{1}{4} \mathbf{E}\left(\tilde{z}_{2}-\tilde{z}_{1}\right)\left(\tilde{h}_{2}-\tilde{h}_{1}\right)\left[v^{\prime \prime}\left(x+\theta \tilde{z}_{1}+\lambda \tilde{h}_{1}\right) v^{\prime \prime}\left(x+\theta \tilde{z}_{2}+\lambda \tilde{h}_{2}\right)\right. \\
& \left.-v^{\prime \prime}\left(x+\theta \tilde{z}_{1}+\lambda \tilde{h}_{2}\right) v^{\prime \prime}\left(x+\theta \tilde{z}_{2}+\lambda \tilde{h}_{1}\right)\right] \\
& \geq 0 .
\end{aligned}
$$

Remark: If $v$ exhibits increasing absolute prudence over the interval of interest, essentially the same proof can be used to show that $J_{\theta \lambda} J_{x x}-J_{\theta x} J_{\lambda x} \leq 0$. This converse to Lemma 5 allows one to establish the converse to Proposition 2.

\section{Proof of Proposition 1}

The agent's problem can be rewritten as

$$
\max _{c, \theta} J(c, \theta ; x, \lambda)
$$

The first-order conditions are

$$
J_{c}(C(x, \lambda), \Theta(x, \lambda) ; x, \lambda)=0
$$

and

$$
J_{\theta}(C(x, \lambda), \Theta(x, \lambda) ; x, \lambda)=0
$$

Differentiating (A.24) and (A.25) with respect to $x$ and $\lambda$ and arranging the results in matrix form yields

$$
\left[\begin{array}{ll}
J_{c c} & J_{c \theta} \\
J_{c \theta} & J_{\theta \theta}
\end{array}\right]\left[\begin{array}{ll}
C_{x} & C_{\lambda} \\
\Theta_{x} & \Theta_{\lambda}
\end{array}\right]=-\left[\begin{array}{ll}
J_{c x} & J_{c \lambda} \\
J_{\theta x} & J_{\theta \lambda}
\end{array}\right]
$$

Define

$$
A=\left[\begin{array}{ll}
J_{c c} & J_{c \theta} \\
J_{c \theta} & J_{\theta \theta}
\end{array}\right]
$$

Then by Lemma 1,

$$
\begin{aligned}
A^{-1} & =\frac{1}{J_{c c} J_{\theta \theta}-J_{c \theta}^{2}}\left[\begin{array}{cc}
J_{\theta \theta} & -J_{c \theta} \\
-J_{c \theta} & J_{c c}
\end{array}\right] \\
& =\Delta^{-1}\left[\begin{array}{cc}
J_{\theta \theta} & R J_{\theta x} \\
R J_{\theta x} & R^{2} J_{x x}+u^{\prime \prime}
\end{array}\right],
\end{aligned}
$$


where

$$
\Delta=J_{c c} J_{\theta \theta}-J_{c \theta}^{2}>0
$$

by Lemma 2. Multiplying both sides of (A.26) on the left by $A^{-1}$ and restricting our attention for now to the left column of the result,

$$
\begin{aligned}
{\left[\begin{array}{c}
C_{x} \\
\Theta_{x}
\end{array}\right] } & =-A^{-1}\left[\begin{array}{l}
J_{c x} \\
J_{\theta x}
\end{array}\right] \\
& =-\Delta^{-1}\left[\begin{array}{cc}
J_{\theta \dot{\theta}} & R J_{\theta x} \\
R J_{\theta x} & R^{2} J_{x x}+u^{\prime \prime}
\end{array}\right]\left[\begin{array}{c}
-R J_{x x} \\
J_{\theta x}
\end{array}\right] \\
& =\Delta^{-1}\left[\begin{array}{c}
R\left(J_{\theta \theta} J_{x x}-J_{\theta x}^{2}\right) \\
-u^{\prime \prime} J_{\theta x}
\end{array}\right] .
\end{aligned}
$$

The effect of wealth on $c$ given by $C_{x}$ is positive by Lemma 2. The effect of wealth on $\theta$ given by $\Theta_{x}$ is positive by Lemma 4, in conjunction with the first-order condition (A.25)..

\section{Proof of Proposition 2}

Since the determinant of the product of two matrices is equal to the product of the determinants, (A.26) implies

$$
\left[J_{c c} J_{\theta \theta}-J_{c \theta}^{2}\right]\left[C_{x} \Theta_{\lambda}-C_{\lambda} \Theta_{x}\right]=-\left[J_{c x} J_{\theta \lambda}-J_{c \lambda} J_{\theta \lambda}\right]
$$

and therefore

$$
\begin{aligned}
{\left[C_{\lambda} \Theta_{x}-C_{x} \Theta_{\lambda}\right] } & =\frac{\left[J_{c x} J_{\theta \lambda}-J_{c \lambda} J_{\theta \lambda}\right]}{\left[J_{c c} J_{\theta \theta}-J_{c \theta}^{2}\right]} \\
& =\frac{R}{\Delta}\left[J_{\theta \lambda} J_{x x}-J_{\theta x} J_{\lambda x}\right] \\
& \geq 0
\end{aligned}
$$

by Lemma 1, Lemma 5 and (A.29).

Remark: As noted in the remark to Lemma 5, increasing absolute prudence on any interval implies that $J_{\theta \lambda} J_{x x}-J_{\theta x} J_{\lambda x} \leq 0$, and therefore that $C_{\lambda} \Theta_{x}-C_{x} \Theta_{\lambda} \leq 0$. Since it is always possible to choose $x, \tilde{z}$ and $\lambda \tilde{h}$ in such a way that only the values of $v$ on a small interval matter, decreasing absolute prudence is a necessary condition for (Â.32) to hold for any $x, \bar{z}$ and $\lambda \tilde{h}$..

\section{Proof of Proposition 3}

Calculating $C_{\lambda}$ and $\Theta_{\lambda}$ just as we calculated $C_{x}$ and $\Theta_{x}$ (that is, by multiplying both sides of A.26 on the left by $A^{-1}$ ),

$$
\left[\begin{array}{l}
C_{\lambda} \\
\Theta_{\lambda}
\end{array}\right]=-A^{-1}\left[\begin{array}{l}
J_{c \dot{\lambda}} \\
J_{\theta \lambda}
\end{array}\right]
$$




$$
\begin{aligned}
& =-\Delta^{-1}\left[\begin{array}{cc}
J_{\theta \theta} & R J_{\theta x} \\
R J_{\theta x} & R^{2} J_{x x}+u^{\prime \prime}
\end{array}\right]\left[\begin{array}{c}
-R J_{x \lambda} \\
J_{\theta \lambda}
\end{array}\right] \\
& =\Delta^{-1}\left[\begin{array}{c}
R\left(J_{\theta \theta} J_{x \lambda}-J_{\theta x} J_{\theta \lambda}\right) \\
R^{2}\left(J_{\theta x} J_{x \lambda}-J_{x x} J_{\theta \lambda}\right)-u^{\prime \prime} J_{\theta \lambda}
\end{array}\right] .
\end{aligned}
$$

Lemma 5 implies that $R^{2}\left(J_{\theta x} J_{x \lambda}-J_{x x} J_{\theta \lambda}\right) \leq 0$. Moreover, since $J_{x x}<0$, Lemma 5 implies that

$$
J_{\theta \lambda} \leq \frac{J_{\theta x} J_{\lambda x}}{J_{x x}}
$$

The first-order condition $J_{\theta}=0$, together with Lemma 4, implies that $J_{\theta x} \geq 0$, and the assumption of Proposition 3 that $J_{\lambda} \leq 0$, together with Lemma 4, implies that $J_{\lambda x} \geq 0$. Therefore, (A.34) guarantees that

$$
-u^{\prime \prime} J_{\theta \lambda} \leq-\frac{u^{\prime \prime} J_{\theta x} J_{\lambda x}}{J_{x x}} \leq 0
$$

Thus, $\Theta_{\lambda} \leq 0$ whenever $J_{\lambda} \leq 0$. 


\section{Appendix B}

Numerical Counterexample and Proofs Related to the Effect of Human Capital Risk on Consumption

\section{Numerical Counterexample: Increased Human Capital Risk Raising Current Consumption}

From (A.33), $C_{\lambda}$ has the same sign as

$$
\begin{aligned}
J_{\theta \theta} J_{x \lambda}-J_{\theta x} J_{\theta \lambda}=\left[\mathbf{E} \tilde{z}^{2} v^{\prime \prime}(x-R c+\lambda \tilde{h}+\theta \tilde{z})\right]\left[\mathbf{E} \tilde{h} v^{\prime \prime}(x-R c+\lambda \tilde{h}+\theta \tilde{z})\right] \\
-\left[\mathbf{E} \tilde{z} v^{\prime \prime}(x-R c+\lambda \tilde{h}+\theta \tilde{z})\right]\left[\mathbf{E} \tilde{z} \tilde{h} v^{\prime \prime}(x-R c+\lambda \tilde{h}+\theta \tilde{z})\right]
\end{aligned}
$$

The effect of a small mean-zero risk $\tilde{h}$ that is independent of $\tilde{z}$ can be analyzed by taking a secondorder Taylor expansion around $\tilde{h}=0$ and then taking the expectation over $\tilde{h}$ to obtain the marginal distribution over $\tilde{z}$. With the assumption $E \tilde{h}=0$ eliminating the expectation of the first-order terms in the Taylor expansion, this yields

$$
\begin{aligned}
J_{\theta \theta} J_{x \lambda}-J_{\theta x} J_{\theta \lambda}=\left[\mathrm{E} \tilde{z}^{2} v^{\prime \prime}(x-R c+\theta \tilde{z})\right]\left[\sigma_{h}^{2} \mathbf{E} v^{\prime \prime \prime}(x-R c+\theta \tilde{z})\right] \\
\\
-\left[\mathbf{E} \tilde{z} v^{\prime \prime}(x-R c+\theta \tilde{z})\right]\left[\sigma_{h}^{2} \mathbf{E} \tilde{z} v^{\prime \prime \prime}(x-R c+\theta \tilde{z})\right]+o\left(\sigma_{h}^{2}\right) .
\end{aligned}
$$

Thus, for sufficiently small mean-zero $\tilde{h}$, the effect of $\tilde{h}$ on saving has the same sign as

$$
\left[\mathbf{E} \tilde{z}^{2} v^{\prime \prime}(x-R c+\theta \tilde{z})\right]\left[\mathbf{E} v^{\prime \prime \prime}(x-R c+\theta \tilde{z})\right]-\left[\mathbf{E} \tilde{z} v^{\prime \prime}(x-R c+\theta \tilde{z})\right]\left[\mathbf{E} \tilde{z} v^{\prime \prime \prime}(x-R c+\theta \tilde{z})\right]
$$

Now, let

$$
v(x)=3 \ln (x)+7 A^{2} \ln \left(w+A^{3}\right),
$$

where $A$ is a large positive number. Let $x-R c=5$. It is always easy to choose a first-period utility function $u$ and values for $x$ and $c$ to satisfy the first-order condition for optimal consumption. Let $\tilde{z}$ equal -4 with probability $.5-\frac{\xi}{A},-2$ with probability $.5-\frac{\xi}{A}$, and $A^{2}$ with probability $\frac{2 \xi}{A}$. Choose $\xi$ so that $\theta=1$ becomes the optimal amount of $\tilde{z}$ as $\tilde{h}$ gets very small. That is, choose $\xi$ to satisfy

$$
\begin{aligned}
\mathbf{E} \tilde{z} v^{\prime}(x-R c+\tilde{z}) & =\left(.5-\frac{\xi}{A}\right)\left[-14=\frac{28 A^{2}}{A^{3}-4}-\frac{14 A^{2}}{A^{3}-1}\right]+\frac{2 \xi}{A}\left[\frac{3 A^{2}}{5+A^{2}}+\frac{7 A^{4}}{2\left(5+A^{2}+A^{3}\right)}\right] \\
& =0
\end{aligned}
$$

As $A \rightarrow+\infty, \xi \rightarrow 1$ in this equation. Then, straightforward but tedious calculations show that as $\tilde{h}$ gets small and $A \rightarrow \infty$, 


$$
E \tilde{z}^{2} v^{\prime \prime}(\cdot) \mathbf{E} v^{\prime \prime \prime}(\cdot)-\mathrm{E} \tilde{z} v^{\prime \prime}(\cdot) \mathbf{E} \tilde{z} v^{\prime \prime \prime}(\cdot)=\frac{8}{81}>0
$$

Thus, if $\tilde{h}$ gets small enough and $A$ gets big enough, $C_{\lambda}$ becomes positive. Since $C_{x}$ is always positive, adding a positive constant to the mean-zero human capital risk $\tilde{h}$ can only make $C_{\lambda}$ more strongly positive.

\section{Proof of Proposition 4}

From (A.33),

$$
\operatorname{sign}\left(C_{\lambda}(x, \lambda)\right)=\operatorname{sign}\left(J_{\theta \theta} J_{x \lambda}-J_{\theta x} J_{\theta \lambda}\right)
$$

If $\lambda$ were chosen optimally, the first-order condition

$$
J_{\lambda}(c, \theta ; x, \lambda)=0
$$

would always hold. All three of the variables $c, \theta$ and $\lambda$ would be functions of $x$ alone. Differentiating (B.2) and the other two first-order conditions with respect to $x$ would yield the matrix equation

$$
\left[\begin{array}{lll}
J_{c c} & J_{c \theta} & J_{c \lambda} \\
J_{c \theta} & J_{\theta \theta} & J_{\theta \lambda} \\
J_{c \lambda} & J_{\theta \lambda} & J_{\lambda \lambda}
\end{array}\right]\left[\begin{array}{c}
\frac{d c^{*}}{d x} \\
\frac{d \theta^{*}}{d x} \\
\frac{d \lambda^{*}}{d x}
\end{array}\right]=-\left[\begin{array}{l}
J_{c x} \\
J_{\theta x} \\
J_{\lambda x}
\end{array}\right] .
$$

Define

$$
B=\left[\begin{array}{lll}
J_{c c} & J_{c \theta} & J_{c \lambda} \\
J_{c \theta} & J_{\theta \theta} & J_{\theta \lambda} \\
J_{c \lambda} & J_{\theta \lambda} & J_{\lambda \lambda}
\end{array}\right]
$$

By Cramer's rule,

$$
\begin{aligned}
\frac{d \lambda^{*}}{d x} & =\frac{-1}{\operatorname{det}(B)}\left|\begin{array}{lll}
J_{c c} & J_{c \theta} & J_{c x} \\
J_{c \theta} & J_{\theta \theta} & J_{\theta x} \\
J_{c \lambda} & J_{\theta \lambda} & J_{\lambda x}
\end{array}\right| \\
& =\frac{-1}{\operatorname{det}(B)}\left|\begin{array}{ccc}
u^{\prime \prime} & J_{c \theta} & J_{c x} \\
0 & J_{\theta \theta} & J_{\theta x} \\
0 & J_{\theta \lambda} & J_{\lambda x}
\end{array}\right| \\
& =\frac{-u^{\prime \prime}}{\operatorname{det}(B)}\left[J_{\theta \theta} J_{x \lambda}-J_{\theta x} J_{\theta \lambda}\right]
\end{aligned}
$$

where the second line results from subtracting $R$ times the third column from the first column of the determinant in the numerator on the first line. Since $B$ is a negative definite $3 \times 3$ matrix, $\operatorname{det}(B)<0$ and

$$
\operatorname{sign}\left(\frac{d \lambda^{*}}{d x}\right)=-\operatorname{sign}\left(J_{\theta \theta} J_{\lambda x}-J_{\theta \lambda} J_{\theta x}\right)=-\operatorname{sign}\left(C_{\lambda}\right) .
$$




\section{Proof of Corollary 4.1}

If

$$
\mathbf{E} \tilde{h} v^{\prime}(\bar{x}-R c+\lambda \tilde{h}+\theta \tilde{z})=\mathbf{E} \tilde{h}\left(\bar{x}-R c-x_{0}+\lambda \tilde{h}+\theta \tilde{z}\right)^{-\gamma}=0
$$

and

$$
\mathbf{E} \tilde{z} v^{\prime}(\bar{x}-R c+\lambda \tilde{h}+\theta \tilde{z})=\mathbf{E} \tilde{z}\left(\bar{x}-R c-x_{0}+\lambda \tilde{h}+\theta \tilde{z}\right)^{-\gamma}=0,
$$

then for any $\xi>R c+x_{0}$,

$$
\mathbf{E} \tilde{h}\left(x-R c-x_{0}+\left[\frac{x-R c-x_{0}}{\bar{x}-R c-x_{0}} \lambda\right] \tilde{h}+\left[\frac{x-R c-x_{0}}{\bar{x}-R c-x_{0}} \theta\right] \tilde{z}\right)^{-\gamma}=0
$$

and

$$
\mathbf{E} \tilde{z}\left(x-R c-x_{0}+\left[\frac{x-R c-x_{0}}{\bar{x}-R c-x_{0}} \lambda\right] \tilde{h}+\left[\frac{x-R c-x_{0}}{\bar{x}-R c-x_{0}} \theta\right] \tilde{z}\right)^{-\gamma}=0 .
$$

Therefore, if they were both freely chosen, the optimal values of $\lambda$ and $\theta$ would be proportional to $x-R c-x_{0}$, guaranteeing that both would increase with $x$.

\section{Proof of Corollary 4.2}

By (A.33), in order to prove the corollary, we must show that

$$
J_{\theta \theta} J_{x \lambda}-J_{\theta x} J_{\theta \lambda} \leq 0
$$

when $\tilde{z}$ has a two point distribution. Given the fact that $J_{\theta \theta}<0$, this is equivalent to

$$
J_{\lambda x}+J_{\lambda \theta} \frac{d \theta}{d x} \geq 0
$$

where

$$
\frac{d \theta}{d x}=-\frac{J_{\theta x}}{J_{\theta \theta}}
$$

is the optimal adjustment in $\theta$ when $x$ changes with $\lambda$ remaining fixed. With $\lambda$ held fixed, $\lambda \tilde{h}$ is a fixed background risk, and the decreasing absolute risk aversion of $v$ is enough to guarantee that $\frac{d \theta}{d x} \geq 0$.

Denote the two possible realizations of $\tilde{z}$ as $z_{1}$, which occurs with probability $p$, and $z_{2}$, which occurs with probability $(1-p)$. Then, the equation $J_{\theta}=0$, which characterizes an optimal value of $\theta$, becomes 


$$
p z_{1} \mathbf{E}\left[v^{\prime}\left(x-R c+\theta z_{1}+\lambda \tilde{h}\right)\right]+(1-p) z_{2} \mathbf{E}\left[v^{\prime}\left(x-R c+\theta z_{2}+\lambda \tilde{h}\right)\right]=0,
$$

where the expectations denoted by $\mathbf{E}$ here are only over $\tilde{h}$. (Note the use of independence between $\tilde{z}$ and $\tilde{h}$ in expanding out the expectation over $\tilde{z}$.) Clearly, (B.13) requires $z_{1}$ and $z_{2}$ to be of opposite signs. Without loss of generality, let $z_{2}>0>z_{1}$.

Taking the derivative of (B.13) with respect to $x$, with $\theta$ adjusting to maintain this first-order condition, yields

$$
p z_{1}\left(1+z_{1} \frac{d \theta}{d x}\right) \mathbf{E}\left[v^{\prime \prime}\left(x-R c+\theta z_{1}+\lambda \tilde{h}\right)\right]+(1-p) z_{2}\left(1+z_{2} \frac{d \theta}{d x}\right) \mathbf{E}\left[v^{\prime \prime}\left(x-R c+\theta z_{2}+\lambda \tilde{h}\right)\right]=0
$$

Since $z_{2}>0>z_{1}$, equation (B.14) implies that both $\left(1+z_{2} \frac{d \theta}{d x}\right)$ and $\left(1+z_{1} \frac{d \theta}{d x}\right)$ are of the same sign and therefore both positive.

Turning to the quantity of interest, (B.11) can be expanded to

$$
\begin{aligned}
J_{\lambda x}+J_{\lambda \theta} \frac{d \theta}{d x}= & p\left(1+z_{1} \frac{d \theta}{d x}\right) \mathbf{E}\left[\tilde{h} v^{\prime \prime}\left(x-R c+\theta z_{1}+\lambda \tilde{h}\right)\right] \\
& +(1-p)\left(1+z_{2} \frac{d \theta}{d x}\right) \mathbf{E}\left[\tilde{h} v^{\prime \prime}\left(x-R c+\theta z_{2}+\lambda \tilde{h}\right)\right] \\
\geq 0 &
\end{aligned}
$$

Dividing (B.15) by the negative quantity

$$
-p z_{1}\left(1+z_{1} \frac{d \theta}{d x}\right) \mathbf{E}\left[v^{\prime \prime}\left(x-R c+\theta z_{1}+\lambda \tilde{h}\right)\right]=(1-p)\left(1+z_{2} \frac{d \theta}{d x}\right) \mathbf{E}\left[v^{\prime \prime}\left(x-R c+\theta z_{2}+\lambda \tilde{h}\right)\right]
$$

(B.15) becomes

$$
\frac{1}{\left(-z_{1}\right)} \frac{\mathbf{E}\left[\tilde{h} v^{\prime \prime}\left(x-R c+\theta z_{1}+\lambda \tilde{h}\right)\right]}{\mathbf{E}\left[v^{\prime \prime}\left(x-R c+\theta z_{1}+\lambda \tilde{h}\right)\right]}+\frac{1}{z_{2}} \frac{\mathbf{E}\left[\tilde{h} v^{\prime \prime}\left(x-R c+\theta z_{2}+\lambda \tilde{h}\right)\right]}{\mathbf{E}\left[v^{\prime \prime}\left(x-R c+\theta z_{2}+\lambda \tilde{h}\right)\right]} \leq 0
$$

In order to prove (B.16), use the stipulation that at the point in question, $J_{\lambda} \leq 0$, or in expanded form,

$$
p \mathbf{E} \tilde{h} v^{\prime}\left(x-R c+\theta z_{1}+\lambda \tilde{h}\right)+(1-p) \mathbf{E} \tilde{h} v^{\prime}\left(x-R c+\theta z_{2}+\lambda \tilde{h}\right)=0
$$

Dividing (B.17) by the positive quantity 


$$
-p z_{1} \mathbf{E}\left[v^{\prime}\left(x-R c+\theta z_{1}+\lambda \tilde{h}\right)\right]=(1-p) \mathbf{E}\left[v^{\prime}\left(x-R c+\theta z_{2}+\lambda \tilde{h}\right)\right]
$$

(B.17) becomes

$$
\frac{1}{\left(-z_{1}\right)} \frac{\mathbf{E}\left[\tilde{h} \tilde{v}^{\prime}\left(x-R c+\theta z_{1}+\lambda \tilde{h}\right)\right]}{\mathbf{E}\left[v^{\prime}\left(x-R c+\theta z_{1}+\lambda \tilde{h}\right)\right]}+\frac{1}{z_{2}} \frac{\mathbf{E}\left[\tilde{h} v^{\prime}\left(x-R c+\theta z_{2}+\lambda \tilde{h}\right)\right]}{\mathbf{E}\left[v^{\prime}\left(x-R c+\theta z_{2}+\lambda \tilde{h}\right)\right]} \leq 0
$$

Note that except for involving the first derivative of $v$ instead of the second, (B.18) is of the same form as (B.16), which needs to be proven.

To prove (B.16) from (B.18), we will show that each of the two terms in (B.16) is less than or equal to the corresponding term in (B.16). For $i=1,2$, define

$$
\eta_{i}=\frac{\mathbf{E}\left[\tilde{h} v^{\prime \prime}\left(x-R c+\theta z_{i}+\lambda \tilde{h}\right)\right]}{\mathbf{E}\left[v^{\prime \prime}\left(x-R c+\theta z_{i}+\lambda \tilde{h}\right)\right]} .
$$

Decreasing absolute risk aversion, which guarantees that $-v^{\prime \prime}$ falls faster than $v^{\prime}$ in proportional terms, implies that for any scalar realization $h$ of the random variable $\tilde{h}$,

$$
\left(h-\eta_{i}\right) \frac{v^{\prime \prime}\left(x-R c+\theta z_{i}+\lambda h\right)}{v^{\prime \prime}\left(x-R c+\theta z_{i}+\lambda \eta_{i}\right)} \leq\left(h-\eta_{i}\right) \frac{v^{\prime}\left(x-R c+\theta z_{i}+\lambda h\right)}{v^{\prime}\left(x-R c+\theta z_{i}+\lambda \eta_{i}\right)} .
$$

Taking expectations of both sides of (B.20) over random $\tilde{h}$,

$$
\begin{aligned}
\frac{\mathbf{E}\left[\tilde{h} v^{\prime \prime}\left(x-R c+\theta z_{i}+\lambda \tilde{h}\right)\right]-\eta_{i} \mathbf{E}\left[v^{\prime \prime}\left(x-R c+\theta z_{i}+\lambda \tilde{h}\right)\right]}{v^{\prime \prime}\left(x-R c+\theta z_{i}+\lambda \eta_{i}\right)} \\
\leq \frac{\mathbf{E}\left[\tilde{h} v^{\prime}\left(x-R c+\theta z_{i}+\lambda \tilde{h}\right)\right]-\eta_{i} \mathbf{E}\left[v^{\prime}\left(x-R c+\theta z_{i}+\lambda \tilde{h}\right)\right]}{v^{i}\left(x-R c+\theta z_{i}+\lambda \eta_{i}\right)}
\end{aligned}
$$

But, by the definition of $\eta_{i}$, the right-hand side of (B.21) is less than or equal to zero. Thus, the left-hand side of (B.21) is also less than or equal to zero, implying

$$
\frac{\mathbf{E}\left[\tilde{h} v^{\prime \prime}\left(x-R c+\theta z_{i}+\lambda \tilde{h}\right)\right]}{\mathbf{E}\left[v^{\prime \prime}\left(x-R c+\theta z_{i}+\lambda \tilde{h}\right)\right]} \leq \eta_{i}=\frac{\mathbf{E}\left[\tilde{h} v^{\prime}\left(x-R c+\theta z_{i}+\lambda \tilde{h}\right)\right]}{\mathbf{E}\left[v^{\prime}\left(x-R c+\theta z_{i}+\lambda \tilde{h}\right)\right]} .
$$

Therefore, (B.18) implies (B.16).-

Intuitively, the key to the proof is that with a two-point distribution for $z$, an increase in $x$ with its consequent increase in $\theta$ leads to an increase in $x-R c+\theta z_{i}$ for both $i=1$ and $i=2$. This increase in $x-R c+\theta z_{i}$ leads to an increase in the marginal benefit of higher $\lambda$ relative to the expected marginal utility $v^{\prime}$ for both $i=1$ and $i=2$. Since the condition for optimal $\theta$ insures that the importance of expected marginal utility for $i=1$ and $i=2$ is in a fixed ratio, this leads to an increase in the overall marginal benefit of $\lambda$. 


\section{References}

Ahsan, Syed M., "Taxation in a Two-Period Temporal Model of Consumption and Portfolio Allocation," Journal of Public Economics, 5 (April-May, 1976), 337-352.

Auerbach, Alan J. and Laurence J. Kotlikoff, Dynamic Fiscal Policy (Cambridge: Cambridge University Press, 1987).

Barro, Robert J., “Are Government Bonds Net Wealth?” Journal of Political Economy 82 (November/December, 1974), 1095-1117.

Barsky, Robert B., N. Gregory Mankiw, and Stephen P. Zeldes, "Ricardian Consumers with Keynesian Propensities," American Economic Review, 76 (September, 1986), 676-691.

Bodie, Zvi, Robert C. Merton, and William F. Samuelson, "Labor Supply Flexibility and Portfolio Choice in a Life-Cycle Model," Journal of Economic Dynamics and Control, 16 (July-October, 1992), 427-449.

Breeden, Douglas T., "Consumption, Production, Inflation and Interest Rates: A Synthesis," Journal of Financial Economics, 16 (May, 1986), 3-39.

Caballero, Ricardo, "Consumption Puzzles and Precautionary Savings," Journal of Monetary Economics, 24 (January, 1990), 113-136.

Chan, Louis Kuo Chi, "Uncertainty and Neutrality of Government Financing Policy," Journal of Monetary Economics 11 (May, 1983): 351-372.

Davies, James and John Whalley, "Taxes and Capital Formation: How Important is Human Capital?" ch. 6 in National Saving and Economic Performance, B. Douglas Bernheim and John B. Shoven, eds. (Chicago: University of Chicago Press, 1991).

Devereux, Michael B., and Gregor W. Smith, "International Risk Sharing and Economic Growth," International Economic Review 35 (August, 1994), 535-550.

Domar, Evsey D. and Richard A. Musgrave, "Proportional Income Taxation and Risk-Taking," Quarterly Journal of Economics 58 (May, 1944), 388-422.

Drèze, Jacques H., and Franco Modigliani, "Consumption Decisions Under Uncertainty," Journal of Economic Theory, 5 (December, 1972), 308-335.

Driffill, E. J. and Harvey S. Rosen, "Taxation and Excess Burden: A Life-Cycle Perspective," International Economic Review, 24 (October, 1983), 671-683.

Easley, David, Nicholas M. Kieferer, and Uri M. Possen, "An Equilibrium Analysis of Fiscal Policy with Uncertainty and Incomplete Markets," International Economic Review, 34 (November, 1993), 935-952. 
Eaton, Jonathan, and Harvey S. Rosen, "Taxation, Human Capital, and Uncertainty," American Economic Review, 70 (September, 1980), 705-715.

Economic Report of the President (Washington, D.C., 1996).

Feldstein, Martin, "The Effects of Taxation on Risk Taking," Journal of Political Economy, $7 \mathbf{7}$ (Sept.-Oct. 1969), 755-764.

Feldstein, Martin, Capital Taxation (Cambridge: Harvard University Press, 1983).

Feldstein, Martin, "The Optimal Level of Social Security Benefits," Quarterly Journal of Economics, 100 (May, 1985), 303-320.

Frankel, Jeffrey A., "Portfolio Crowding-Out, Empirically Estimated," Quarterly Journal of Economics, 100 (August, 1985), 1041-1066.

Friedman, Benjamin M., "Crowding Out or Crowding In? Economic Consequences of Financing Government Deficits," Brookings Papers on Economic Activity, 3:1978, 593-641.

Friend, Irwin, and Marshall E. Blume, "The Demand for Risky Assets," American Economic Review, 65 (December, 1975), 900-922.

Grossman, Sanford J., and Robert J. Shiller, "Consumption Correlatedness and Risk Measurement in Economies with Non-Traded Assets and Heterogeneous Information," Journal of Financial Economics, 10 (July, 1982), 195-210.

Guiso, Luigi, Tullio Jappelli and Daniele Terlizzese, "Income Risk, Borrowing Constraints and Portfolio Choice," CEPR Discussion Paper \# 888 (January, 1994).

Hart, Oliver E., "Some Negative Results on the Existence of Comparative Statics Results in Portfolio Theory," Review of Economic Studies, 42 (October, 1975), 615-621.

Jaffe, Adam B., "Technological Opportunity and Spillovers of R \& D," American Economic Review, 76 (December, 1986), 984-1001.

Kanbur, S. M., "Risk Taking and Taxation: An Alternative Perspective," Journal of Public Economics, 15 (April, 1981), 163-184.

Kāplōw, Loùis, "A Note on Taxătioñ as Social Insurance for Uncertain Labor Income," NBER Working Paper \# 3708 (May, 1991).

Kihlstrom, Richard E., David Romer, and Steve Williams, "Risk Aversion with Random Initial Wealth," Econometrica, 44 (June, 1981), 911-920.

Kimball, Miles S., "Precautionary Saving in the Small and in the Large," Econometrica, 58 (January $1990 \mathrm{a}), 53-73$.

Kimball, Miles S., "Precautionary Saving and the Marginal Propensity to Consume," NBER Work- 
ing Paper \# 3403 (1990b).

Kimball, Miles S., "Standard Risk Aversion," Econometrica, 61 (May, 1993), 589-611.

Kimball, Miles S., "Precautionary Motives for Holding Assets," The New Palgrave Dictionary of Money and Finance, Peter Newman, Murray Milgate and John Eatwell, eds. (1992), Stockton Press, New York: 158-161.

Kimball, Miles S., and N. Gregory Mankiw, "Precautionary Saving and the Timing of Taxes," Journal of Political Economy, 97 (August, 1989): 863-879.

Kimball, Miles S., and Phillipe Weil, "Precautionary Saving and Consumption Smoothing over Time and Possibilities," NBER Working Paper \# 3976 (1992).

Leland, Hayne E., "Saving and Uncertainty: The Precautionary Demand for Saving," Quarterly Journal of Economics, 82 (August, 1968), 465-473.

MacDonald, Glenn M., "The Economics of Rising Stars," American Economic Review, 78 (March; 1988), 155-166.

Marshall, Albert W. and Ingram Olkin, Inequalities: Theory of Majorization and its Applications (New York: Academic Press, 1979).

Merton, Robert C., "On the Role of Social Security as a Means for Efficient Risk Sharing in an Economy Where Human Capital Is Not Tradable," Financial Aspects of the United States Pension System, Zvi Bodie and John Shoven, eds. (Chicago: University of Chicago Press, 1983).

Nachman, David C., "Preservation of 'More Risk Averse' Under Expectations," Journal of Economic Theory, 28 (December, 1982), 361-368.

Pratt, John W., "Risk Aversion in the Small and in the Large," Econometrica, 32 (January-April, 1964), 122-137.

Pratt, John W., and Richard J. Zeckhauser, "Proper Risk Aversion," Econometrica, 60 (January, 1987), 143-154.

Rothschild, Michael and Joseph E. Stiglitz, "Increasing Risk II: Its Economic Consequences," Journal of Economic Theory 3 (March, 1971), 66-84.

Sandmo, Agnar, "Capital Risk, Consumption, and Portfolio Choice," Econometrica, 37 (October, 1969), 586-599.

Sandmo, Agnar, "The Effect of Uncertainty on Saving Decisions," Review of Economic Studies, $\mathbf{3 7}$ (July, 1970), 353-360.

Sandmo, Agnar, "The Effects of Taxation on Savings and Risk Taking," Handbook of Public Eco- 
nomics, A. J. Auerbach and M. Feldstein, eds. (Amsterdam: North-Holland, 1985).

Shleifer, Andrei and Robert W. Vishny, "The Efficiency of Investment in the Presence of Aggregate Demand Spillovers," Journal of Political Economy 96 (December, 1988), 1221-1231.

Skinner, Jonathan, "Risky Income, Life Cycle Consumption, and Precautionary Savings," Journaul of Monetary Economics, 22 (September, 1988), 237-255.

Varian, Hal R., "Redistributive Taxation as Social Insurance," Journal of Public Economics, 14 (Âugust, 1980), 49-68.

Weil, Philippe, "Precautionary Savings and the Permanent Income Hypothesis," Review of Economic Studies, 60 (April, 1993), 367-383.

Zeldes, Stephen P., "Optimal Consumption with Stochastic Income: Deviations from Certainty Equivalence," Quarterly Journal of Economics, 104 (1989), 275-298. 


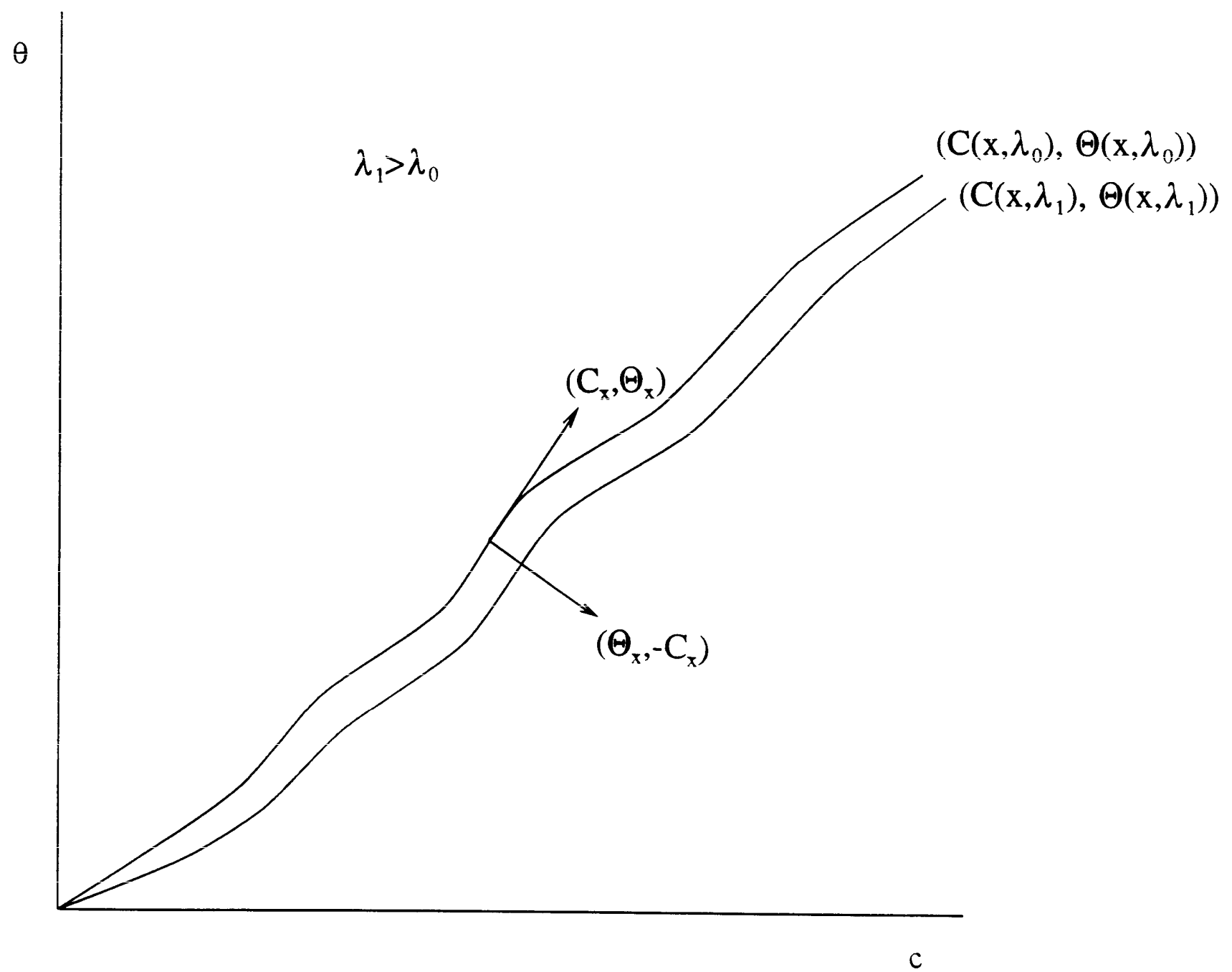

Figure 1 